\title{
TRATAMENTOS DOS EFLUENTES GERADOS NA PRODUÇÃO DE BIODIESEL
}

Joel A. Palomino-Romero, Otávio M. Leite, Katlin I. Barrios Eguiluz, Giancarlo R. Salazar-Banda*, Daniel P. Silva e Eliane B. Cavalcanti

Instituto de Tecnologia e Pesquisa, Universidade Tiradentes, Av. Murilo Dantas, 300, 49032-490 Aracaju - SE, Brasil

Recebido em 27/4/11; aceito em 5/9/11; publicado na web em 30/9/11

TREATMENTS OF THE EFFLUENTS GENERATED IN THE BIODIESEL PRODUCTION. The wastewaters from biodiesel production contain as primarily wastes sodium or potassium soaps, fatty acids, glycerin, alcohol and other contaminants. In general, these waters are chemically unsuitable for release to any water body, so, it is necessary the adoption of techniques for the treatment of this effluent. In this review, electrochemical, biological, physicochemical, and combined treatments reported for the removal of the wastewater containing pollutants come from biodiesel production have been summarized. In addition, the recovery, the reuse, the energy production and the synthesis of new compounds from the organic matter contained in this kind of effluent are also reviewed.

Keywords: electrochemical treatment; biological treatment; recovery.

\section{INTRODUÇÃO}

De modo geral, o termo biocombustível refere-se a combustíveis líquidos ou gasosos empregados no setor de transporte e que são predominantemente produzidos a partir de biomassa. ${ }^{1}$ Estes biocombustíveis oferecem muitos benefícios, incluindo a redução das emissões de gases que provocam o efeito estufa, ${ }^{2}$ uma alta disponibilidade a partir de fontes comuns de biomassa, além de características não poluentes, biodegradáveis e que contribuem para a sustentabilidade. ${ }^{3}$ Os biocombustíveis são utilizados principalmente em veículos, mas também podem ser usados em motores ou células de combustível para geração de eletricidade. ${ }^{1}$

Neste contexto, a biomassa pode ser convertida em biocombustíveis via rota bioquímica e química, ${ }^{1}$ como o etanol e o biodiesel, ou em produtos de conversão termoquímica, como o petróleo sintético, biogás sintético e demais produtos bioquímicos. A Figura 1 mostra os principais processos relacionados a esta conversão de biomassa.

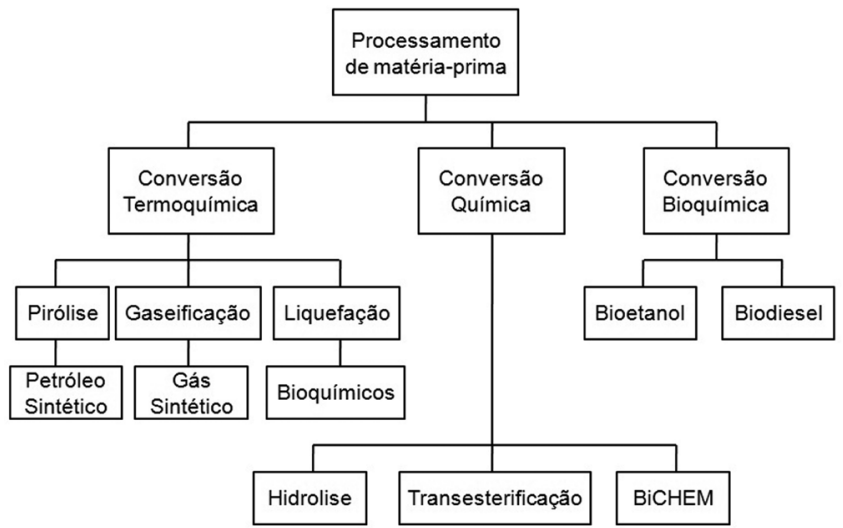

Figura 1. Principais processos de conversão de biomassa. Adaptado da ref. 1

Deste modo, tanto o bioetanol como o biodiesel podem ser definidos como combustíveis derivados de fontes renováveis, sendo o bioetanol um aditivo substituto da gasolina e o biodiesel um combustível para motores diesel. ${ }^{1,4} \mathrm{O}$ biodiesel tem diversas vantagens em comparação com o diesel oriundo do petróleo, além

*e-mail: gianrsb@gmail.com de ser plenamente competitivo na maioria dos aspectos técnicos: ${ }^{5}$ derivação de um recurso renovável nacional, reduzindo assim a dependência do petróleo (fonte finita e esgotável) e aumentando sua preservação; biodegradabilidade; redução da maioria das emissões de gases automotores (com exceção dos óxidos de nitrogênio, $\mathrm{NO}_{x}$ ); ponto de fulgor superior, incrementando a segurança de manuseio e armazenagem; excelente lubricidade, fator de importância com a chegada dos combustíveis de baixo teor de enxofre, que reduziram em muito a lubricidade.

Para a obtenção do biodiesel, o óleo e gordura vegetal ou animal são submetidos a uma reação química denominada transesterificação. ${ }^{6}$ Nessa reação, óleo e gordura vegetal ou animal reagem na presença de um catalisador (geralmente uma base) ${ }^{7}$ com um álcool (geralmente metanol) ${ }^{8}$ produzindo os correspondentes ésteres alquílicos (se for metanol, ésteres metílicos) da mistura de ácidos graxos que são encontrados no óleo e gordura vegetal ou animal e obtendo-se como subproduto da reação a glicerina. ${ }^{5}$ A Figura 2 mostra um esquema da reação de transesterificação por catálise.

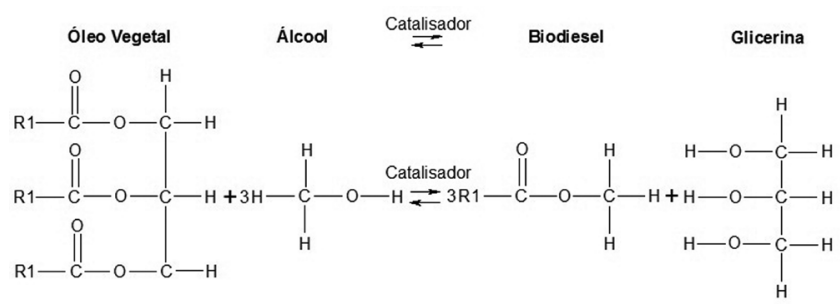

Figura 2. Reação de transesterificação por catálise

Dentre as fontes para a produção de biodiesel encontra-se uma grande variedade de matérias-primas, que incluem os óleos vegetais mais comuns (por exemplo, soja, ${ }^{9}$ algodão, ${ }^{10}$ palma, ${ }^{11}$ canola, ${ }^{12}$ amendoim, ${ }^{13}$ girassol ${ }^{14}$ e coco) ${ }^{15}$ e gorduras animais (geralmente sebo), ${ }^{16}$ bem como óleos residuais (por exemplo, óleos de fritura usados $)^{17}$ e microalgas, ${ }^{18}$ com sua escolha dependendo em muito da geografia do local. ${ }^{5}$

O biodiesel também pode ser produzido por outros modos diferentes daqueles oriundos da transesterificação por catálise básica, ${ }^{19}$ como, por exemplo, por catálise ácida, ${ }^{14}$ catálise heterogênea ou enzimática, ${ }^{20}$ radiação ultrassônica ${ }^{15}$ ou, ainda, por decomposição térmica do óleo com catálise básica. ${ }^{11,21}$ Destas, a transesterificação por catálise básica 
é a mais amplamente usada na produção comercial, provavelmente devido a sua alta taxa de conversão de óleo (triglicerídeos) a biodiesel (ésteres metílicos) em uma reação química simples, de curto tempo, apresentando-se com menores problemas relacionados à corrosão de equipamentos. ${ }^{22}$

No processo final da produção do biodiesel este é submetido a um processo de lavagem com água visando a remoção de impurezas (purificação), seguida por filtração e secagem do biodiesel. A etapa de lavagem é repetida de duas a cinco vezes dependendo da quantidade de impurezas no biodiesel, impurezas estas relacionadas a resíduos de glicerina, sabões e ácidos graxos. Assim, as águas de lavagem obtidas após a etapa de purificação contêm basicamente resíduos de sabões de sódio ou potássio, além dos ácidos graxos, glicerina, alcoóis (metanol ou etanol) e outros contaminantes. ${ }^{23}$

Nesta etapa, é gerada uma grande quantidade de efluente, de 20 a $120 \mathrm{~L}$ por cada $100 \mathrm{~L}$ de biodiesel. ${ }^{24} \mathrm{Em}$ geral, estas águas resultantes do processo de lavagem do biodiesel apresentam-se quimicamente inadequadas para serem lançadas a qualquer corpo hídrico; ${ }^{25}$ sendo, do ponto de vista de preservação ambiental, necessária a adoção de técnicas de tratamento para este efluente. ${ }^{26}$

Assim, este artigo visou revisar os principais tipos de tratamentos utilizados para a purificação ou descontaminação da água de lavagem proveniente do processo de produção de biodiesel, incluindo aqueles ainda em fase de pesquisa científica, dado o fator de inovação deste tema. Adicionalmente, foram também revisados os estudos focados na recuperação e/ou reuso dos compostos presentes nestes efluentes, assim como a síntese de novos compostos a partir destes contaminantes.

\section{TIPOS DE TRATAMENTO}

\section{Tratamentos eletroquímicos}

Srirangsan e colaboradores ${ }^{4}$ pesquisaram a aplicação do processo de eletrocoagulação no tratamento do efluente de uma planta de produção de biodiesel que empregava óleo de fritura e óleo de palma cru como matéria-prima, usando metanol e catalisador básico. Os autores testaram cinco combinações de ânodos e cátodos de diversos materiais: $\mathrm{Fe}-\mathrm{Fe}, \mathrm{Fe}-\mathrm{C}, \mathrm{Al}-\mathrm{Al}, \mathrm{Al}-\mathrm{C}$ e $\mathrm{C}-\mathrm{C}$; estes eletrodos com forma de placas retangulares tinham uma área de $50 \mathrm{~cm}^{2}$. Os testes foram realizados em um reator em batelada com capacidade de $1 \mathrm{~L}$, com os eletrodos conectados em paralelo a uma fonte de alimentação de corrente contínua, como mostrado na Figura 3. Foram testadas cinco densidades de corrente que variavam de 3,5 a $11,0 \mathrm{~mA} \mathrm{~cm}^{-2}$, assim como também foi observado o efeito do $\mathrm{pH}$ inicial do efluente no desempenho do tratamento. A fim de obter as condições ótimas desta combinação de variáveis, os autores monitoraram as concentrações iniciais e finais relacionadas aos teores de óleos e graxas (TOG),

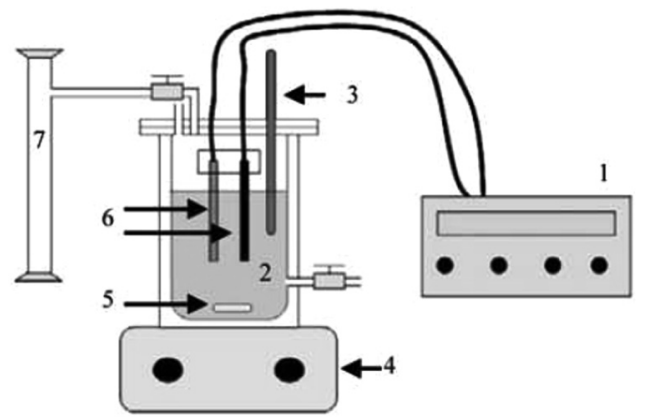

Figura 3. Diagrama experimental do reator de eletrocoagulação: 1. fonte de alimentação, 2. eletrólito, 3. termômetro, 4. agitador magnético, 5. barra magnética, 6. eletrodos, 7. coletor de gases sólidos suspensos (SS), concentração de glicerol e metanol, demanda química de oxigênio (DQO), e valor de $\mathrm{pH}$ final do efluente.

Os autores citados concluíram que as condições ótimas para o tratamento do efluente foram alcançadas com a combinação de um ânodo de alumínio e um cátodo de grafite (Al-C), aplicando uma densidade de corrente de $8,32 \mathrm{~mA} \mathrm{~cm}^{-2}$, um tempo de retenção de $25 \mathrm{~min}$, em pH inicial do efluente de $6 .{ }^{4}$ Ainda segundo Srirangsan e colaboradores, ${ }^{4}$ com estas condições conseguiram eficiências de remoção de DQO, SS e TOG de 55,7; 97,5 e 97,8\%, respectivamente; enquanto as eficiências de remoção relacionadas aos teores de glicerina e metanol foram inferiores e correspondentes a 3,5 e 16,9\%, respectivamente. Este estudo demonstrou que o tratamento por eletrocoagulação pode ser eficiente se usado como tratamento primário para o efluente da produção de biodiesel, necessitando, entretanto, de um tratamento secundário para remoção da glicerina e metanol ainda presentes no meio. O consumo dos eletrodos de alumínio foi calculado em 147,45 $\mathrm{mg} \mathrm{L}^{-1}$ e a energia requerida foi de $6,92 \mathrm{kWh} \mathrm{m}^{-3}$ de efluente.

Chavalparit e Ongwandee estudaram o tratamento por eletrocoagulação do mesmo efluente estudado por Srirangsan e colaboradores, ${ }^{4}$ mas otimizaram as variáveis de operação com o uso de um método de planejamento experimental conhecido como metodologia de superfície de resposta (MSR). ${ }^{24}$ Neste estudo montaram um ânodo de alumínio e um cátodo de grafite (Al-C) no mesmo reator empregado por Srirangsan e colaboradores. ${ }^{4}$ Por intermédio da aplicação da MSR desenvolveram um modelo quadrático completo para a predição da eficiência de remoção de contaminantes do efluente, usando como variáveis de controle do modelo o $\mathrm{pH}$ inicial do efluente, o potencial aplicado e o tempo de reação. Paralelamente foram feitos diversos testes no reator, alterando as variáveis de controle do modelo para poder comparar os resultados obtidos por estes experimentos com os resultados previstos pela MSR ao se empregarem as variáveis otimizadas. A comparação destes resultados é apresentada na Tabela 1.

Tabela 1. Comparação das condições otimizadas e as eficiências de remoção obtidas a partir dos experimentos e da MSR. Adaptada da ref. 8

\begin{tabular}{lcc}
\hline & $\begin{array}{c}\text { Valores } \\
\text { experimentais }\end{array}$ & $\begin{array}{c}\text { Valores otimizados } \\
\text { pela MSR }\end{array}$ \\
\hline Condições ótimas & & \\
$\mathrm{pH}$ & 6 & 6,06 \\
Potencial (V) & 20 & 18,2 \\
Tempo de reação (min) & 25 & 23,54 \\
Remoção da DQO (\%) & 55,43 & 55,01 \\
Remoção de óleos e graxas (\%) & 96,75 & 97,45 \\
Remoção de sólidos suspensos $(\%)$ & 97,76 & 97,77 \\
\hline
\end{tabular}

A Tabela 1 mostra coerência entre os valores das variáveis otimizadas experimentalmente com os resultados de remoção alcançados e os valores das variáveis otimizadas pela MSR com seus respectivos valores de remoção. Isto evidencia que o modelo de regressão quadrática determinado não somente auxilia na diminuição do número de experimentos necessários para otimizar os parâmetros operacionais. ${ }^{25}$ Entretanto, este tratamento não se mostra eficiente na remoção de glicerol e metanol, fato evidenciado pela modesta eficiência de remoção da DQO.

Por outro lado, Pattaraluk e colaboradores estudaram o tratamento por oxidação eletroquímica do efluente de biodiesel proveniente de uma planta que empregava óleo de fritura como matéria-prima. ${ }^{27}$ O reator de vidro empregado no estudo possuía uma capacidade de $2 \mathrm{~L}$ e dentro deste foram alojados os eletrodos constituídos por duas grades de $\mathrm{Ti} / \mathrm{RuO}_{2}$, com uma superfície de área de $816,5 \mathrm{~cm}^{2}$ em 
ambas as grades. A alimentação de corrente contínua foi feita através de uma fonte HY 3020 e as concentrações de DBO, DQO e TOG do efluente foram monitoradas durante todo o processo eletro-oxidativo, que teve uma duração de $8 \mathrm{~h}$.

$\mathrm{O}$ efeito da densidade de corrente na oxidação eletroquímica do efluente foi observado no intervalo de 1,84 e $5,51 \mathrm{~mA} \mathrm{~cm}^{-2}$, em um $\mathrm{pH}$ inicial de 2,5 ( $\mathrm{pH}$ do efluente bruto entre 9,25 e 10,76). Os resultados obtidos mostraram que um incremento na densidade de corrente conduz a um incremento na diminuição das concentrações de DBO, DQO e TOG do efluente. Aplicando uma densidade de corrente de 5,51 mA cm$~_{-2}$ consegue-se remover, após $7 \mathrm{~h}$ de eletrólise, valores correspondentes a 67 e $84 \%$ de DBO e DQO, respectivamente, enquanto a remoção completa do TOG é alcançada após $5 \mathrm{~h}$. Esta diminuição nas concentrações destes parâmetros é atribuída à oxidação eletroquímica dos poluentes orgânicos presentes no efluente, que ocorre devido à interação com radicais hidroxila ou oxigênio ativo quimissorvido gerados no ânodo. ${ }^{27}$

Pattaraluk e colaboradores ainda determinaram a densidade de corrente ótima em termos das eficiências de corrente instantâneas, calculadas a partir dos dados de DQO. A densidade de corrente de $4,28 \mathrm{~mA} \mathrm{~m}^{-2}$ foi a que mostrou melhor desempenho. ${ }^{27}$

Para melhorar a eficiência na remoção dos poluentes, os autores adicionaram ao efluente $\mathrm{NaCl}$ com variação de concentração entre 0,015 a 0,092 M. Os resultados mostraram que a adição de $\mathrm{NaCl}$ promove uma diminuição mais eficiente das concentrações de DBO, DQO e TOG no efluente. As melhores eficiências foram obtidas ao adicionarem concentrações de $\mathrm{NaCl}$ acima de 0,061 M. Após 7 h de eletrolise obteve-se uma remoção de DBO e DQO de aproximadamente 90 e $100 \%$, respectivamente, enquanto que a remoção completa do TOG foi alcançada após $2 \mathrm{~h}$. A diminuição nas concentrações destes parâmetros foi atribuída à oxidação eletroquímica dos poluentes orgânicos presentes no efluente que ocorre devido à interação com espécies de cloro ativo $\left(\mathrm{Cl}_{2} / \mathrm{OCl}^{-}\right)$, geradas eletroquimicamente no reator. ${ }^{27}$

A concentração ótima de $\mathrm{NaCl}$ também foi determinada em função da análise das eficiências de corrente instantâneas. As melhores eficiências foram obtidas ao adicionarem concentrações de $\mathrm{NaCl}$ acima de $0,061 \mathrm{M}$, conseguindo diminuir as concentrações de DBO e DQO em 84 e 90\%, respectivamente, após 5 h de eletrolise e removendo completamente o TOG após $2 \mathrm{~h}$.

\section{Tratamentos biológicos}

Suehara e colaboradores estudaram a aplicação do processo de tratamento biológico em águas de lavagem da purificação de biodiesel. ${ }^{26}$ Estas águas foram obtidas diretamente de uma planta de produção, em pequena escala, que empregava o processo de transesterificação por catálise básica como método para a obtenção do biodiesel.

Este efluente possuía elevadas concentrações de óleo e sólidos dissolvidos, baixas concentrações de nitrogênio, um pH elevado e uma baixa quantidade de nutrientes requeridos para o crescimento microbiano, exceto pelas fontes de carbono. Assim, para evitar a eutrofização do efluente tratado, foram adicionadas pequenas quantidades de fontes de nitrogênio (sulfato de amônio, cloreto de amônio ou ureia), extrato de levedura, di-hidrogenofosfato de potássio $\left(\mathrm{KH}_{2} \mathrm{PO}_{4}\right)$ e sulfato de magnésio hidratado $\left(\mathrm{MgSO}_{4} \cdot 7 \mathrm{H}_{2} \mathrm{O}\right) .{ }^{26}$

Os pesquisadores empregaram a levedura Rhodotorula mucilaginosa para degradar o óleo. Após diversos testes, as condições ótimas para a cultura e o crescimento desta levedura foram determinadas, sendo estas: $\mathrm{pH}$ 6,8, concentração inicial de levedura de $1 \mathrm{~g} \mathrm{~L}^{-1}$, o emprego de ureia como fonte de nitrogênio em vez de sulfato de amônio ou cloreto de amônio e, uma relação de C/N entre 17 e 68 (peso do carbono presente no óleo extraído com hexano em relação ao peso do nitrogênio adicionado como ureia).
Os testes conduzidos por estes autores os levaram a perceber que quanto maior a concentração de sólidos presentes no efluente, menor a taxa de crescimento específica máxima dos micro-organismos. Observaram que estes não conseguiam crescer se a concentração de sólidos presentes no efluente estava acima de $2,14 \mathrm{~g} \mathrm{~L}^{-1}$. Para evitar a inibição do crescimento microbiano, o efluente bruto teve de ser diluído com o mesmo volume de água e, depois, foram adicionados a este os nutrientes necessários $\left(7,6 \times 10^{-3} \mathrm{~mol}\right.$ de ureia, $1,0 \mathrm{~g}$ de levedura, $1,47 \times 10^{-2}$ mol de $\mathrm{KH}_{2} \mathrm{PO}_{4}$ e $8,11 \times 10^{-4} \mathrm{~mol} \mathrm{de} \mathrm{MgSO}_{4} \cdot 7 \mathrm{H}_{2} \mathrm{O}$ por litro). Assim, foram feitos os ensaios de biodegradação com o efluente bruto e diluído (cada um com suas respectivas dosagens de nutrientes) por $66 \mathrm{~h}$, que mostraram que embora a degradação do óleo não tenha acontecido no efluente bruto, no efluente diluído esta alcançou uma eficiência superior a $98 \%$.

Selma e colaboradores estudaram o efeito da carga orgânica e do tempo de alimentação na eficiência de um reator anaeróbio em batelada sequencial (Anaerobic Sequential Batch Reactor - ASBR) aplicado ao tratamento de um efluente da produção de biodiesel. ${ }^{28}$ $\mathrm{O}$ reator empregado com 5,0 L de capacidade foi o modelo Bioflo III da New Brunswick Scientific, o qual continha lodo granulado e possuía dois impulsores do tipo de turbina, cada um com seis lâminas planas, como mostrado na Figura 4. A temperatura foi mantida a 30 ${ }^{\circ} \mathrm{C}$ por um banho termostático e o inóculo usado nos experimentos foi oriundo de um reator anaeróbio de fluxo ascendente, com manta de lodo que tratava efluentes de um abatedouro de aves.

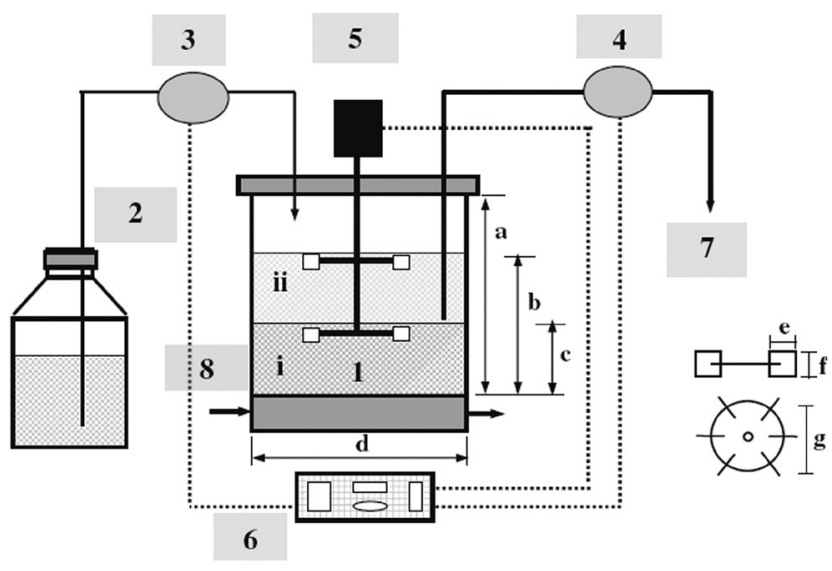

(a)

(b)

Figura 4. Diagrama do reator anaeróbio em batelada sequencial agitado magneticamente: (a) Reator [1 - BIOFLO III Bioreactor (New Brunswick Scientific Co.), capacidade $5 L(a=26 \mathrm{~cm}, b=16 \mathrm{~cm}, c=8 \mathrm{~cm}, d=20 \mathrm{~cm})$ impulsor do tipo de turbina com seis lâminas planas $(e=2 \mathrm{~cm}, f=1,5 \mathrm{~cm}$, $g=6 \mathrm{~cm}$ ), lodo granulado ( $i$ - região de alta concentração de biomassa, $i i$ região de baixa concentração de biomassa); 2 - alimentação, 3 - bomba de alimentação, 4 - bomba de descarga, 5 - sistema de agitação, 6 - sistema de automação, 7 - efluente, 8 - controle de temperatura com jaqueta de fundo]. (b) Impulsor do tipo de turbina com seis lâminas planas em detalhe

A alimentação do reator foi feita em batelada com DQO de 500, 1000 e $2000 \mathrm{mg} \mathrm{L}^{-1}$ de $\mathrm{O}_{2}$ e as porcentagens de remoção da matéria orgânica alcançadas foram de 93, 81 e 66\%, respectivamente. Os autores testaram também uma carga orgânica de alimentação de DQO igual a $3000 \mathrm{mg} \mathrm{L}^{-1}$, mas sob estas condições a estabilidade operacional não conseguiu ser alcançada.

Os autores perceberam que o aumento no tempo de alimentação do reator refletia em um aumento na remoção da carga orgânica; assim, quando a alimentação foi feita no modo de batelada com uma carga orgânica de entrada de DQO igual a $1000 \mathrm{mg} \mathrm{L}^{-1}$ e tempos de preenchimento de 2 e 4 h, a remoção de matéria orgânica alcançada foi de $85 \%$ 
em ambos os casos. Mas, quando a carga orgânica foi de DQO igual a $2000 \mathrm{mg} \mathrm{L}^{-1}$ com tempos de preenchimento de 2 e $4 \mathrm{~h}$, as remoções de matéria orgânica alcançadas foram de 80 e $77 \%$, respectivamente.

\section{Tratamentos físico-químicos}

Goldani e colaboradores realizaram uma pesquisa envolvendo diversos métodos para tratar o efluente proveniente da lavagem do biodiesel. ${ }^{29}$ Para a obtenção das amostras (água de lavagem) produziram biodiesel a partir de óleo de soja usado, ao qual foi adicionado hidróxido de sódio, como catalisador, e metanol; este biodiesel passou pelo processo de lavagem, sendo extraídas as amostras de estudo. Os cinco métodos de tratamento avaliados pelos pesquisadores foram: ${ }^{29}$ tratamento com uma solução de ácido acético $0,01 \%$ (método 1 ); tratamento com uma solução de ácido acético $0,01 \%$ seguido de uma filtração em filtro de britas e areia (método 2); tratamento com uma solução de ácido acético $0,01 \%$ seguido de uma filtração em filtro de britas e areia, e com uma membrana filtrante entre camadas (método 3); tratamento em Jar Test com adição de sulfato ferroso como floculante (método 4); tratamento em Jar Test, com adição de sulfato de alumínio como floculante (método 5).

A Tabela 2 mostra as eficiências de remoção de cor, turbidez, DQO, hidrocarbonetos, TOG e de oxigênio dissolvido alcançadas pelos diversos métodos aplicados ao tratamento do efluente de lavagem de biodiesel. Como pode ser observado, as eficiências de remoção mais significativas para a maioria dos parâmetros analisados foram alcançadas pelos tratamentos químicos com agentes floculantes $\left(\mathrm{FeSO}_{4}\right.$ e $\left.\mathrm{Al}_{2}\left(\mathrm{SO}_{4}\right)_{3}\right)$; isto devido a que estes agentes conseguem remover eficientemente as partículas em suspensão no efluente, mas por outro lado, componentes presentes neste tipo de efluente em concentrações significativas, como metanol e glicerol, não conseguiram ser removidas em sua totalidade, fato evidenciado na modesta remoção da DQO.

No entanto, os métodos que envolvem adição de agentes floculantes se mostram economicamente viáveis, tendo em vista que, para uma indústria de porte médio com produção diária de 100.000 $\mathrm{L}$ de biodiesel, o custo do tratamento da água de lavagem não chega a $0,7 \%$ do faturamento anual da empresa, além da possibilidade de reuso da água tratada no próprio processo. ${ }^{29}$

Considerando que as eficiências da remoção dos poluentes dos efluentes da produção de biodiesel são raramente de $100 \%$ usando os diversos tratamentos descritos acima, alguns grupos de pesquisa estudaram a viabilidade do uso de tratamentos combinados para atingir eficiências de degradação superiores. Estes estudos estão descritos a seguir.

\section{Tratamentos combinados}

Siles e colaboradores estudaram a combinação de duas técnicas de tratamento de efluentes. Empregaram a eletrocoagulação como pré-tratamento e a codigestão anaeróbia para o tratamento de efluente derivado da produção do biodiesel e com a adição de glicerol. ${ }^{30}$

O efluente estudado foi de uma indústria que empregava óleo de fritura como matéria-prima para a fabricação de biodiesel. O efluente gerado da lavagem do biodiesel era rico em biodiesel, glicerol, ácidos graxos livres e metanol e possuía uma DQO total de $2,53 \times 10^{5} \mathrm{mg} \mathrm{L}^{-1}$ e uma DQO solúvel de $2,13 \times 10^{5} \mathrm{mg} \mathrm{L}^{-1}$. O efluente foi acidificado com ácido sulfúrico e depois centrifugado para poder se recuperar a fase oleosa (óleo e biodiesel) e separar a fase aquosa. $\mathrm{O} \mathrm{pH}$ desta fase aquosa foi neutralizado e, posteriormente, submetido à eletrocoagulação em um reator com agitação de $5 \mathrm{~L}$ de capacidade, no qual foram alojados oito eletrodos de alumínio com área superficial total de $80,5 \mathrm{~cm}^{2}$ e através dos quais foi aplicada uma corrente de $1,5 \mathrm{~A}$ (12 V) por 30 min.Após esse tempo, a DQO total diminuiu em 6,25\%, enquanto a DQO solúvel diminuiu em 13,60\% logo após 20 min de eletrocoagulação. A diminuição da DQO total após pré-tratamento por acidificação-centrifugação e eletrocoagulação foi de $45 \%$. Depois deste pré-tratamento, a fase sobrenadante contendo sólidos dissolvidos foi separada da fase aquosa. Esta fase aquosa foi caracterizada e misturada com glicerol em uma proporção de 85-15 (DQO), até se obter uma DQO solúvel final de $3 \times 10^{5} \mathrm{mg} \mathrm{L}^{-1}$. Posteriormente, o efluente foi neutralizado com hidróxido de sódio para prepará-lo para a etapa de codigestão.

O tratamento por codigestão foi realizado em três reatores Pyrex de $1 \mathrm{~L}$ de capacidade, os quais possuíam quatro conexões para realizar a alimentação, ventilar o biogás, injetar o gás inerte (nitrogênio) para manter as condições anaeróbias e para saída do efluente. Os reatores foram inoculados com biomassa obtida de um reator anaeróbio empregado para tratar efluente de cervejaria. Durante cada experimento a carga orgânica adicionada ao reator foi gradualmente aumentada com DQO de 1000 a 2000 e $3000 \mathrm{mg} \mathrm{L}^{-1} \mathrm{de} \mathrm{O}_{2}$. Em todos os casos o volume de metano foi medido em função do tempo e amostras foram tomadas e analisadas antes e depois da alimentação. A duração de cada experimento foi igual ao intervalo de tempo requerido para a máxima produção de gás e remoção da DQO, a qual variou entre 18 e 45 h.

Os autores observaram que a maior parte da DQO removida era empregada na produção de metano e o metabolismo microbiano era principalmente orientado para a geração de gás. Também foi observada a biodegradabilidade do efluente, a qual foi calculada pelo ajuste da curva da quantidade de substrato removido em função da concentração de substrato inicial para cada experimento. O resultado deste ajuste foi uma reta, cuja inclinação denotou a porcentagem de biodegradabilidade do efluente, a qual foi próxima de $100 \%$, permitindo que fosse obtida uma concentração de metano de $310 \mathrm{~mL} \mathrm{~g}^{-1}$ de DQO removida a $1 \mathrm{~atm}$ e $25^{\circ} \mathrm{C}$.

\section{PRODUÇÃO DE ENERGIA, RECUPERAÇÃO E SÍNTESE DE NOVOS COMPOSTOS}

Nos últimos anos têm sido publicados estudos visando não somente a remoção dos compostos poluentes contidos nos efluentes

Tabela 2. Eficiência de remoção dos métodos aplicados ao tratamento de efluente proveniente da lavagem do biodiese ${ }^{29}$

\begin{tabular}{|c|c|c|c|c|c|}
\hline \multirow{2}{*}{ Parâmetros analisados } & \multicolumn{5}{|c|}{ Eficiência de remoção (\%) } \\
\hline & Método 1 & Método 2 & Método 3 & Método 4 & Método 5 \\
\hline Cor & 27 & 31 & 83 & 100 & 100 \\
\hline Turbidez & 5 & 17 & 0 & 100 & 100 \\
\hline DQO & 26 & 38 & 41 & 63 & 69 \\
\hline Hidrocarbonetos & 16 & 22 & 29 & 100 & 100 \\
\hline Óleos e graxas & 10 & 20 & 20 & 100 & 100 \\
\hline Oxigênio dissolvido & 9 & 18 & 27 & 9 & 0 \\
\hline
\end{tabular}


da produção de biodiesel, mas também o aproveitamento dos mesmos para diversas finalidades, tais como a produção de energia, a recuperação e/ou reuso e a síntese de novos compostos. A seguir são descritos os principais estudos encontrados na literatura disponível.

Uma nova tecnologia empregada para a produção de energia elétrica, a partir dos efluentes da produção de biodiesel, são as células combustíveis microbianas (CCM). As CCM são sistemas bioeletroquímicos que empregam micro-organismos como catalisadores para oxidar compostos orgânicos ou inorgânicos produzindo eletricidade. Os elétrons liberados pelas bactérias são transferidos ao ânodo e depois transferidos ao cátodo, onde são usados para reduzir os aceptores de elétrons, comumente o oxigênio. ${ }^{31}$

Feng e colaboradores empregaram esta técnica para realizar o tratamento (oxidação) do efluente de biodiesel, produzido em um reator em escala de bancada, pelo processo de transesterificação por catálise básica. ${ }^{31}$ Os pesquisadores empregaram vinte câmaras separadas de CCM e as equiparam com cátodos de ar e ânodos de tecido de carbono (área de superfície $=7 \mathrm{~cm}^{2}$ ) ou com escova de fios de carbono. Uma análise do efluente revelou que era composto de 61-63\% de glicerina e 37-39\% de impurezas. Os principais componentes destas impurezas foram identificados como diglicerol, dietil acetal e propanamida, entre outros. Levando em consideração esta composição, fizeram experimentos empregando dois tipos de efluente: alimentaram as CCM com um substrato composto por efluente de biodiesel e outro por glicerina, ambos contendo $10 \%$ de águas residuais urbanas coletadas da rede municipal de esgotos de Harbin, China.

Após esses experimentos, uma análise da DQO revelou que mais de 90\% da concentração da DQO no efluente de biodiesel foi removida e um valor de $93 \%$ foi obtido quando foi empregada glicerina como fonte de alimentação. Paralelamente a esta diminuição foi registrada também a geração de eletricidade. A densidade de potência máxima registrada quando as CCM foram alimentadas com efluente de biodiesel foi de $487 \pm 28 \mathrm{~mW} \mathrm{~m}^{-2}$ (cátodo) e de $533 \pm 14 \mathrm{~mW} \mathrm{~m}^{-2}$ quando alimentadas com glicerina. O uso de escova de fios de carbono como ânodo incrementou a densidade de potência e a eficiência coulômbica em 68 e $18 \%$, respectivamente, se comparadas quando empregado o tecido de carbono como ânodo. Um tratamento térmico realizado na escova de fios de carbono mostrou que melhora o desempenho das CCM, conseguindo-se registrar uma densidade de potência de $2110 \pm 68 \mathrm{~mW}$ $\mathrm{m}^{-2}$ de cátodo e uma eficiência coulômbica de $18,7 \pm 0,9 \%$ quando as CCM foram alimentadas com efluente de biodiesel. ${ }^{31}$

Nimje e colaboradores também avaliaram a geração de eletricidade empregando a bactéria Bacillus subtilis (BBK006) como biocatalizador em uma CCM. ${ }^{32}$ Existe uma diferença com os estudos realizados por Feng e colaboradores ${ }^{31}$ neste estudo foi empregada uma única CCM, alimentada sequencialmente com $0,5 \mathrm{~mL} \mathrm{~L}^{-1}$ de um substrato à base de glicerol e $25 \mathrm{~mL}$ do meio $\mathrm{M} 9$, cuja composição era $5,61 \times 10^{-2} \mathrm{~mol} \mathrm{~L}^{-1}$ de $\mathrm{NH}_{4} \mathrm{Cl}, 2,2 \times 10^{-2} \mathrm{~mol} \mathrm{~L}^{-1} \mathrm{de}$ $\mathrm{KH}_{2} \mathrm{PO}_{4}, 4,23 \times 10^{-2} \mathrm{~mol} \mathrm{~L}^{-1}$ de $\mathrm{Na}_{2} \mathrm{HPO}_{4}, 8,55 \times 10^{-2} \mathrm{~mol} \mathrm{~L}^{-1} \mathrm{de}$ $\mathrm{NaCl}, 1 \times 10^{-3} \mathrm{~mol} \mathrm{~L}^{-1}$ de $\mathrm{MgSO}_{4}$ e $1 \times 10^{-4} \mathrm{~mol} \mathrm{~L}^{-1}$ de $\mathrm{CaCl}_{2}$; o pH foi ajustado em 7 com uma solução $0,5 \mathrm{~mol} \mathrm{~L}^{-1}$ de $\mathrm{NaOH} .{ }^{32}$

Segundo estes autores, a CCM foi construída em um balão de $500 \mathrm{~mL}$ que possuía três compartimentos para alojar o ânodo, contato elétrico e eletrodo de referência, e outro compartimento lateral empregado para alojar o cátodo. $\mathrm{O}$ ânodo (área eletroativa $=22,5 \mathrm{~cm}^{2}$ ) e o cátodo (diâmetro do disco $=3 \mathrm{~cm}$ ) foram feitos de tecido de carbono. Os ensaios foram realizados em modo de alimentação em batelada à temperatura ambiente. ${ }^{32}$

Ainda segundo os autores, ${ }^{32}$ os resultados demonstraram que na ausência da bactéria não foi registrada nenhuma corrente pelo sistema de controle. Entretanto, quando foi inoculada a bactéria a geração de corrente foi observada após uma longa fase de latência de cerca de 3 dias e teve uma duração de aproximadamente 22 dias. A geração de eletricidade na CCM inclui 4 fases: inclinação, estacionária, elevação e declínio. Após a inoculação do $1^{\circ}$ ciclo de alimentação, a CCM precisou de aproximadamente $120 \mathrm{~h}$ para alcançar o primeiro pico de produção de corrente na fase de inclinação. Posteriormente o reator foi alimentado sucessivamente em ciclos com glicerol para se obter o máximo de corrente. Os resultados mostraram uma quantidade de corrente maior, gerada nos últimos ciclos de alimentação $\left(3^{\circ}, 4^{\circ}\right.$ e $5^{\circ}$ ciclos) em comparação com os primeiros. Durante a fase estacionária, a corrente se estabilizou em $0,3 \mathrm{~mA}$ e, após o $4^{\circ}$ ciclo de alimentação alcançou o valor máximo de $0,5 \mathrm{~mA}$. A adição de mais glicerol nos ciclos posteriores de alimentação $\left(5^{\circ}\right.$ e $\left.6^{\circ}\right)$ não resultou na obtenção de uma corrente estável, mas em uma relativa diminuição da corrente gerada no $4^{\circ}$ ciclo de alimentação..$^{32}$

Para avaliar o desempenho da CCM, Nimje e colaboradores observaram a densidade de potência durante o processo de alimentação sequencial. ${ }^{32} \mathrm{~A}$ máxima densidade de potência registrada foi de 0,01 ; 0,05 e $0,06 \mathrm{~mW} \mathrm{~cm}^{-2}$ obtidas pelas correspondentes correntes de 0,23; 0,48 e $0,60 \mathrm{~mA}$ no $2^{\circ}, 3^{\circ}$ e $4^{\circ}$ ciclo de alimentação, respectivamente. A geração de energia aumentou e a biomassa eletroativa se acumulou a cada ciclo, até que o substrato foi consumido.

$\mathrm{O}$ efeito do $\mathrm{pH}$ no meio também foi avaliado e seus resultados mostraram que sob condições de $\mathrm{pH}$ ácido ( $\mathrm{pH}$ entre 5 e 6) são geradas correntes baixas (aproximadamente 0,3 mA). Além disso, uma queda rápida da corrente foi observada dentro das três primeiras horas com o meio nestes valores de $\mathrm{pH}$, enquanto que sob condições de neutralidade ( $\mathrm{pH}$ 7) o desempenho da CCM melhorou, chegando a atingir correntes de 0,5 mA. Sob condições de alcalinidade ( $\mathrm{pH}$ entre 8 e 9), correntes estáveis e maiores (aproximadamente $0,4 \mathrm{~mA}$ ) que as registradas sob condições ácidas foram obtidas. Isto mostrou que as bactérias se adaptaram melhor a ambientes alcalinos do que a condições ácidas. ${ }^{32}$

Na produção do biodiesel via reação de transesterificação duas fases são produzidas, a fase inferior é composta por glicerol e outras substâncias químicas como água, sais orgânicos e inorgânicos e uma pequena quantidade de ésteres e álcool, assim como vestígios de glicerídeos. Hájek e Skopal propuseram um método para o tratamento da fase que contém glicerol (FG) baseado na neutralização com ácidos. ${ }^{33} \mathrm{~A}$ adição de ácidos fortes (sulfúrico, hidroclórico, fosfórico e acético) transforma os sabões (procedentes da saponificação do óleo durante a produção de biodiesel) em ácidos graxos livres e sais inorgânicos e, os carbonatos em dióxido de carbono e sais inorgânicos, como mostram as Equações 1 e 2. Nessas equações, 'R' são restos hidrofóbicos de ácidos graxos.

Neutralização dos sabões:

$$
\mathrm{R}-\mathrm{COOK}+\mathrm{H}^{+} \rightarrow \mathrm{R}-\mathrm{COOH}+\mathrm{K}^{+}
$$

Acidificação dos carbonatos:

$$
\mathrm{K}_{2} \mathrm{CO}_{3}+\mathrm{KHCO}_{3}+3 \mathrm{H}^{+} \rightarrow 3 \mathrm{~K}^{+}+2 \mathrm{CO}_{2}+2 \mathrm{H}_{2} \mathrm{O}
$$

Outra opção de tratamento da FG é uma prévia saponificação dos ésteres restantes com um material altamente alcalino (Equação 3) antes de realizar a neutralização.

Saponificação dos ésteres:

$$
\mathrm{R}-\mathrm{COOCH}_{3}+\mathrm{OH}^{-} \rightarrow \mathrm{R}-\mathrm{COO}^{-}+\mathrm{CH}_{3} \mathrm{OH}
$$

Em seguida, a FG é separada em duas fases por gravidade: a fase superior, que contém ácidos graxos e ésteres, é chamada de fase orgânica e a fase inferior, que contém substâncias polares (glicerol, água e sais inorgânicas), chamada de fase de glicerol concentrada.

Os pesquisadores conseguiram obter glicerol com uma pureza de aproximadamente $86 \%$ em peso junto com uma mistura de és- 
teres e ácidos graxos livres (via neutralização) ou só ácidos graxos livres com uma pureza de $99 \%$ em peso (via saponificação seguida de neutralização). Este processo de neutralização foi realizado com ácido fosfórico concentrado e o subproduto obtido desta neutralização foi o $\mathrm{K}_{2} \mathrm{HPO}_{4}{ }^{33}$

Siles e colaboradores avaliaram o desempenho e estabilidade do processo de digestão anaeróbia do glicerol contido no efluente de biodiesel para a produção de metano. ${ }^{34}$ Os experimentos foram realizados em seis reatores Pyrex de $1 \mathrm{~L}$ de capacidade, que possuíam quatro conexões que permitiram a alimentação do reator, ventilação de biogás, injeção de gás inerte (nitrogênio) e a remoção do efluente. Todos os ensaios foram realizados a temperatura de $35^{\circ} \mathrm{C}$ e sob agitação magnética.

Segundo os autores ${ }^{34}$ os reatores foram inoculados com biomassa granular ativada metanogênicamente procedente de um reator utilizado para tratar efluente da cervejaria Heineken S.A. (Jaen, Espanha) e lodo não granular de um reator anaeróbio empregado para tratar águas residuais urbanas de Jerez de la Frontera (Cadiz, Espanha). O substrato utilizado foi o da fase rica em glicerol presente no efluente de biodiesel procedente da indústria Bida S.A., de Fuentes de Anadalucia (Sevilla, Espanha); basicamente este efluente continha glicerol, água, metanol, sais e ácidos graxos.

Assim o substrato sofreu dois pré-tratamentos. O primeiro foi a acidificação com ácido fosfórico e centrifugação para poder recuperar o catalisador usado na transesterificação; adicionalmente, foram também removidos metanol e água por centrifugação. $\mathrm{O}$ segundo pré-tratamento foi a destilação $\left(135-140{ }^{\circ} \mathrm{C} ; 1,6-2,0 \times 10^{-3}\right.$ atm) seguida por extração líquido/líquido com hexano para poder remover as impurezas orgânicas. Devido aos altos níveis da DQO, o glicerol acidificado e destilado foi diluído com água destilada e neutralizado com $\mathrm{NaOH}$. Finalmente, vários nutrientes e $\mathrm{NaHCO}_{3}$ foram adicionados ao glicerol para fornecer as condições necessárias para um metabolismo apropriado dos micro-organismos anaeróbios.

Os experimentos foram realizados empregando três combinações de substrato: lodo granular com glicerol acidificado (LG/GA), lodo não granular com glicerol acidificado (LNG/GA) e lodo granular com glicerol destilado (LG/GD). O maior coeficiente de rendimento de metano foi registrado pelo substrato composto por LG/GD (356 $\mathrm{mL} \mathrm{CH}_{4}$ $\mathrm{g}^{-1}$ DQO removida); já os substratos LG/GA e LNG/GA registraram valores de 292 e $288 \mathrm{~mL} \mathrm{CH}_{4} \mathrm{~g}^{-1}$ DQO removida, respectivamente. Experimentalmente, a efetividade de cada processo em cada caso foi: $76 \%$ usando LG/GA, 75\% usando LNG/GA e $93 \%$ usando LG/GD. Levando em consideração só este resultado, o substrato LG/GD se apresenta como a melhor opção; mas outros fatores têm de ser considerados. A porcentagem da DQO removida é tão importante quanto o coeficiente de produção de metano, pois através de ambos pode ser determinada a biodegradabilidade dos resíduos. A biodegradabilidade do glicerol foi calculada em aproximadamente $100 \%$ para o substrato LG/GA, $75 \%$ para o LNG/GA e $85 \%$ para o LG/GD. ${ }^{34}$

Outra variável avaliada pelos autores foi a variação da carga nos reatores. Os resultados mostraram que uma maior quantidade de metano é produzida quando se incrementa a carga nos reatores, sendo que o tempo para completar a remoção da fração biodegradável foi de $40 \mathrm{~h}$ para ambos os tipos de lodo. A partir da concentração de biomassa nos reatores, foi possível determinar os valores da constante cinética específica da produção de metano. O cálculo desta apontou uma diminuição da constante cinética relacionada com o aumento da carga dos reatores em todos os experimentos, evidenciando um processo inibitório. No caso do substrato LG/GA quando a carga foi variada com DQO de 1000-3000 $\mathrm{mg} \mathrm{L}^{-1}$ de $\mathrm{O}_{2}$, a diminuição foi de $42 \%$; no caso do substrato LNG/GA esta foi de $58 \%$ e no caso do LG/GD a diminuição foi de $76 \%$ quando a carga foi variada com DQO de 1000-2000 mg L-1 de $\mathrm{O}_{2}$. Esta marcada diminuição, quando empregado glicerol destilado, pode ser explicada pelo acúmulo do $\mathrm{NaHCO}_{3}$ adicionado nos reatores como nutriente. Por outro lado, a inibição observada quando empregado glicerol acidificado pode ser resultado de duas causas: o incremento na carga ou o acúmulo de fósforo devido ao pré-tratamento ou mesmo ambos os fatores simultaneamente. ${ }^{34}$

A fermentação do glicerol para 1,3-propanodiol tem sido estudada usando diversos micro-organismos, ${ }^{35}$ no entanto, a produção biológica de $\mathrm{H}_{2}$ e bioetanol a partir do glicerol torna-se atraente devido ao fato do $\mathrm{H}_{2}$ ser uma fonte limpa de energia e o bioetanol ser usado como suplemento da gasolina.

Neste sentido, o micro-organismo Enterobacter aerogenes HU101 é conhecido como produtor de altas taxas de $\mathrm{H}_{2}$ a partir de lodo metanogênico; este micro-organismo pode converter vários carboidratos em $\mathrm{H}_{2}$, etanol, 2,3-butanodiol, lactato e acetato. E. aerogenes HU-101 produz principalmente $\mathrm{H}_{2}$ e etanol com uma produção mínima de outros subprodutos quando o glicerol é empregado como substrato. Ito e colaboradores avaliaram as condições de cultura do E. aerogenes para a produção eficiente de $\mathrm{H}_{2}$ e etanol a partir do efluente de biodiesel. ${ }^{35}$

O efluente de biodiesel contendo glicerol usado nos experimentos foi fornecido por uma fábrica que produzia biodiesel em Hiroshima, Japão. Este biodiesel foi produzido por catálise básica empregando hidróxido de potássio. O efluente continha $41 \%$ (em peso) de glicerol. A concentração de carbono orgânico total no efluente era de $45 \mathrm{~mol} \mathrm{~L}^{-1}$, dos quais 43,67 mol L-1 eram solúveis. As impurezas eram basicamente compostas por cinzas ( $8 \%$ em peso) e metanol (25\% em peso).

Foram feitos testes de fermentação com e sem adição de suplementos que auxiliam no crescimento microbiano. Os autores observaram que quando o efluente era diluído com água deionizada até $8,68 \times 10^{-4} \mathrm{~mol} \mathrm{~L}^{-1}$ de glicerol, este não era completamente consumido mesmo depois de $48 \mathrm{~h}$ de processo fermentativo e nenhum crescimento microbiano era observado após $48 \mathrm{~h}$. Isto indicava que alguns nutrientes precisavam ser adicionados para que a fermentação acontecesse com velocidades significativas.

Os pesquisadores passaram a usar um meio sintético $\left(4,02 \times 10^{-2} \mathrm{~mol}\right.$ de $\mathrm{K}_{2} \mathrm{HPO}_{4}, 4,04 \times 10^{-2} \mathrm{~mol}$ de $\mathrm{KH}_{2} \mathrm{PO}_{4}, 7,6 \times 10^{-3}$ mol de $\left(\mathrm{NH}_{4}\right)_{2} \mathrm{SO}_{4}, 1 \times 10^{-3} \mathrm{~mol} \mathrm{de} \mathrm{MgSO}_{4} \cdot 7 \mathrm{H}_{2} \mathrm{O}, 1,43 \times 10^{-4} \mathrm{~mol}$ de $\mathrm{CaCl}_{2} \cdot 2 \mathrm{H}_{2} \mathrm{O}, 4,96 \times 10^{-4} \mathrm{~mol}$ de $\mathrm{Na}_{2} \mathrm{MoO}_{4} \cdot 2 \mathrm{H}_{2} \mathrm{O}, 1,62 \times 10^{-5} \mathrm{~mol}$ de ácido nicotínico, $9,94 \times 10^{-7} \mathrm{~mol} \mathrm{de} \mathrm{Na}_{2} \mathrm{SeO}_{3}, 1,54 \times 10^{-7} \mathrm{~mol}$ de $\mathrm{NiCl}_{2}$ e $10 \mathrm{~mL}$ de uma solução que continha $2,5 \times 10^{-3} \mathrm{~mol}$ de $\mathrm{MnCl}_{2} \cdot 4 \mathrm{H}_{2} \mathrm{O}, 1,3 \times 10^{-3} \mathrm{~mol} \mathrm{de} \mathrm{H}_{3} \mathrm{BO}_{4}, 3,62 \times 10^{-5} \mathrm{~mol} \mathrm{de} \mathrm{AlK}\left(\mathrm{SO}_{4}\right)_{2}$. $\mathrm{H}_{2} \mathrm{O}, 5,86 \times 10^{-6} \mathrm{~mol}$ de $\mathrm{CuCl}_{2} \cdot 2 \mathrm{H}_{2} \mathrm{O}$ e $1,3 \times 10^{-3} \mathrm{~mol}$ de $\mathrm{Na}_{2}$ EDTA por litro) na diluição do efluente $\left(8,69 \times 10^{-4} \mathrm{~mol} \mathrm{~L}^{-1}\right.$ de glicerol $)$, conseguindo consumir completamente o glicerol após 24 h e obtiveram concentrações de $\mathrm{H}_{2}$ e de etanol de $4,45 \times 10^{-4}$ e de $2,17 \times 10^{-5} \mathrm{~mol} \mathrm{~L}^{-1}$ por $1,09 \times 10^{-5} \mathrm{~mol} \mathrm{~L}^{-1}$ de glicerol, respectivamente. Um incremento significativo na produção de $\mathrm{H}_{2}$ e etanol foi observado quando diversas concentrações $\left(0,5 ; 1,0 ; 2,5\right.$ e $\left.5,0 \mathrm{~g} \mathrm{~L}^{-1}\right)$ de extrato de levedura e triptona foram adicionadas ao meio sintético. A adição de $5 \mathrm{~g} \mathrm{~L}^{-1} \mathrm{de}$ extrato de levedura e triptona resultou no consumo quase completo do glicerol e na produção de aproximadamente $3,25 \times 10^{-2} \mathrm{~mol} \mathrm{~L}^{-1}$ de $\mathrm{H}_{2}$ e $1,6 \times 10^{-3} \mathrm{~mol} \mathrm{~L}^{-1}$ de etanol.

Também foram estudados o efeito da concentração do efluente na fermentação e o efeito inibidor das impurezas na produção de $\mathrm{H}_{2}$ e etanol. Os resultados obtidos a partir do glicerol presente no efluente de biodiesel e de glicerol puro indicam que quanto maior a concentração de glicerol no meio, menores são as concentrações de $\mathrm{H}_{2}$ e etanol obtidas a partir da fermentação. Quanto às impurezas inibidoras do processo fermentativo presentes no efluente, os autores observaram que a presença de sais, tais como cloreto de sódio em altas concentrações, inibe o crescimento microbiano. Isto foi observado a 
partir de experimentos onde foi variada a concentração de $\mathrm{NaCl}$ no meio. Os resultados mostraram que a produção de $\mathrm{H}_{2}$ e etanol era quase a mesma em meios onde foi empregado glicerol puro, com ou sem adição de $1 \%$ de $\mathrm{NaCl}$. Por outro lado, quando o $\mathrm{NaCl}$ foi adicionado em meios onde era empregado o efluente de biodiesel, a produção de $\mathrm{H}_{2}$ e etanol decresceu significativamente, inclusive em concentrações inferiores a $1 \%$ de $\mathrm{NaCl}$. Já em concentrações superiores a $1 \%$ de $\mathrm{NaCl}$, a produção de $\mathrm{H}_{2}$ e etanol decresce pronunciadamente, independentemente do tipo de meio.

A produção biológica de $\mathrm{H}_{2}$ foi também estudada por Ngo e colaboradores, ${ }^{36}$ a partir da bactéria Thermotoga neapolitana, empregando um substrato que continha glicerol procedente de efluente de biodiesel e outro contendo glicerol puro. O efluente de biodiesel procedente da M Energy Co. (Pyeongteak, Coreia do Sul) passou por um pré-tratamento que consistia na remoção de metanol ou etanol por rotoevaporação a $45{ }^{\circ} \mathrm{C}$ e remoção de sólidos por centrifugação a $15000 \mathrm{rpm}$ por $15 \mathrm{~min}$.

A T. neapolitana foi cultivada com sucesso em $0,05 \mathrm{~mol} \mathrm{~L}^{-1} \mathrm{de}$ glicerol puro e em glicerol procedente do efluente de biodiesel, respectivamente. Os resultados mostraram que em ambos os substratos, aproximadamente após $6 \mathrm{~h}$ de cultivo, a produção de $\mathrm{H}_{2}$ incrementou rapidamente; mas após $24 \mathrm{~h}, \mathrm{o} \mathrm{pH}$ das culturas caiu rapidamente a níveis abaixo do ideal para o crescimento $(\mathrm{pH}$ entre 6,8 e 7,5) e a produção de $\mathrm{H}_{2}$ diminuiu lentamente no substrato contendo glicerol de efluente de biodiesel; já no substrato que continha glicerol puro, a desaceleração da produção de $\mathrm{H}_{2}$ não foi tão pronunciada. A concentração máxima de células de T. neapolitana foi observada após 24-36 h de cultivo em ambos os substratos. A biomassa obtida a partir desta linhagem de bactérias foi maior com o substrato de glicerol de efluente de biodiesel (970 $\mathrm{mg} \mathrm{DCWL}^{-1}$ ) do que com o substrato de glicerol puro (710 mg DCWL $\mathrm{m}^{-1}$ ). No entanto, o glicerol não foi completamente consumido.

Os ácidos acético e láctico foram gerados como subprodutos da T. neapolitana em ambos os substratos. Estes ácidos foram gerados simultaneamente com a produção de $\mathrm{H}_{2}$ (entre 4 e $8 \mathrm{~h}$ de cultivo) e seus níveis aumentaram rapidamente entre 8 e $30 \mathrm{~h}$. As quantidades produzidas de ácido acético (aproximadamente $7 \times 10^{-3} \mathrm{~mol} \mathrm{~L}^{-1}$ ) e láctico (aproximadamente $6 \times 10^{-3} \mathrm{~mol} \mathrm{~L}^{-1}$ ) foram similares em ambos substratos e, como pôde ser constatado, a produção de ácido acético foi maior do que a de ácido láctico após $50 \mathrm{~h}$ de processo.

No final do processo $(50 \mathrm{~h})$ o $\mathrm{pH}$ diminuiu de 7,5 para 6,2 , o qual inibe o crescimento desta bactéria e a produção de $\mathrm{H}_{2}$. A produção de $\mathrm{H}_{2}$ após $49 \mathrm{~h}$ de cultivo foi de $1,02 \mathrm{~mol} \mathrm{H}_{2}$ mol $^{-1}$ glicerol consumido para o substrato contendo glicerol puro e de $1,28 \mathrm{~mol}$ $\mathrm{H}_{2}$ mol $^{-1}$ glicerol consumido para o substrato contendo glicerol de efluente de biodiesel. Também foram feitos ensaios com o substrato de glicerol de efluente de biodiesel sem que este sofresse processo de pré-tratamento. A produção de $\mathrm{H}_{2}$ registrada pelo substrato que sofreu pré-tratamento $\left(1,97 \mathrm{~mol} \mathrm{H}_{2} \mathrm{~mol}^{-1}\right.$ glicerol consumido após $56 \mathrm{~h}$ ) foi superior à registrada pelo substrato que não passou por este processo (1,27 $\mathrm{mol} \mathrm{H}_{2} \mathrm{~mol}^{-1}$ glicerol consumido). Isto demonstrou que o pré-tratamento é um fator importante na conversão do glicerol de efluente de biodiesel pela bactéria T. neapolitana. ${ }^{36}$

Os autores observaram que a rápida diminuição do $\mathrm{pH}$ somada à pressão parcial exercida pelo $\mathrm{H}_{2}$ resulta na inibição do crescimento da cultura e, consequentemente, na diminuição da produção de $\mathrm{H}_{2}$. Para minimizar estes efeitos inibidores o $\mathrm{pH}$ foi regulado $\mathrm{N}_{2}$ foi injetado toda vez que o espaço limite para a produção de $\mathrm{H}_{2}$ fosse atingido. Nos ensaios, a T. neapolitana foi cultivada em $40 \mathrm{~mL}$ de um meio contendo $5,43 \times 10^{-2} \mathrm{~mol} \mathrm{~L}^{-1}$ de glicerol de efluente de biodiesel e $2,0 \mathrm{~g} \mathrm{~L}^{-1} \mathrm{de}$ farinha de soja (fonte de $\mathrm{N}_{2}$ ). Foram realizados 3 tipos de ensaios para observar qual combinação de fatores otimizava a eficiência do processo: sem injeção de $\mathrm{N}_{2}$ e sem ajuste de $\mathrm{pH}$, com injeção de $\mathrm{N}_{2}$ e sem ajuste de $\mathrm{pH}$ e com injeção de $\mathrm{N}_{2}$ e ajuste de $\mathrm{pH}$. Os resultados mostraram que a combinação de fatores que apresentou melhor desempenho foi quando injetado $\mathrm{N}_{2}$ e controlado o $\mathrm{pH}$, obtendo-se uma produção de $1,98 \mathrm{~mol} \mathrm{H}_{2} \mathrm{~mol}^{-1}$ glicerol consumido após 197 $\mathrm{h}$; quando não foi injetado $\mathrm{N}_{2}$ nem controlado o $\mathrm{pH}$ se obteve uma produção de 1,24 $\mathrm{mol} \mathrm{H}_{2} \mathrm{~mol}^{-1}$ glicerol consumido. Estes resultados confirmam a eficiência da injeção de $\mathrm{N}_{2}$ durante a produção de $\mathrm{H}_{2}$ em pequenos sistemas de cultivo em batelada. ${ }^{36}$

A monolaurina é o principal monoglicerídeo produzido a partir de óleos láuricos. Em função de sua ocorrência natural no leite materno, em elevadas concentrações, diversos estudos de aplicação terapêutica desse monoglicerídeo como um agente antiviral, bacteriano, protozoal e microbiano vêm sendo desenvolvidos. ${ }^{37}$ Freitas e colaboradores pesquisaram a síntese da monolaurina a partir da reação de esterificação direta do glicerol com ácido láurico em sistema isento de solvente. ${ }^{37}$

Imobilizaram lipases de diferentes fontes, como Candida antarctica B (Calb L), Thermomyces lanuginosa (Lipolase), pâncreas de porco (LPP), Candida rugosa (LCR), Pseudomonas fluorescens (Lipase AK) e Burkholderia cepacia (Lipase PS), sem tratamento adicional, em um suporte feito de um composto híbrido de polissiloxano-álcool polivinílico (POS-PVA) o qual foi sintetizado e ativado com glutaraldeído.

As sínteses foram realizadas contendo misturas de glicerol e ácido láurico numa razão molar fixa de 3:1 e diferentes preparações de lipase numa proporção fixa de $2 \%(\mathrm{~m} / \mathrm{m})$ em relação à massa total dos reagentes. As reações foram conduzidas sob agitação magnética (150 rpm) na faixa de temperatura entre 45 a $60^{\circ} \mathrm{C}$, dependendo da estabilidade térmica de cada preparação de lipase imobilizada. O progresso da síntese foi acompanhado pela retirada de alíquotas (1 mL) ao longo da reação e quantificado o teor de ácido láurico residual por titulometria, empregando solução alcoólica de $\mathrm{KOH} \mathrm{0,02} \mathrm{mol.}$

Com base nos resultados obtidos, foi realizado um estudo do efeito das variáveis temperatura $\left(\mathrm{x}_{1}\right)$ e razão molar entre glicerol e ácido láurico $\left(\mathrm{x}_{2}\right)$ com objetivo de determinar a melhor combinação dessas variáveis para a obtenção máxima de monolaurina. Um planejamento fatorial $2^{2}$ completo com 2 experimentos no ponto central foi utilizado para melhor entendimento da influência dessas variáveis e de suas interações na síntese enzimática de monoglicerídeos. ${ }^{37}$

Das cinco preparações de lipases, o derivado imobilizado da lipase Calb L em POS-PVA mostrou-se mais eficiente para catalisar a esterificação do glicerol com ácido láurico, obtendo elevada conversão molar do ácido láurico e formação de $21 \% \mathrm{~m} / \mathrm{m}$ de monolaurina. A otimização da reação permitiu prever as condições necessárias que favorecem o alcance de elevadas concentrações de monolaurina, sendo a reação maximizada $(31,35 \%$ de produto) para meios reacionais constituídos de glicerol e ácido láurico numa razão molar de 5:1 e temperatura de incubação de $45^{\circ} \mathrm{C}$, por um período de incubação de $24 \mathrm{~h}$. Os autores observaram que a fração molar de monolaurina pode ser ainda incrementada pela utilização de concentrações mais elevadas de biocatalisador.

A glicerina também pode ser utilizada na alimentação animal. Trabalhos recentes para avaliar a adição de níveis crescentes de glicerina na dieta de suínos em crescimento têm sido desenvolvidos e os resultados iniciais indicam que a glicerina pode ser utilizada como ingrediente energético de rações de suínos em crescimento e terminação até o nível de $9 \%$, sem afetar o desempenho e as características de carcaça dos animais. ${ }^{38}$

Em aves, o glicerol pode ser utilizado como fonte de energia em dietas de alta produção. Cerrate e colaboradores conduziram dois experimentos onde glicerol era adicionado à dieta das aves..$^{39}$ Observaram que a glicerina proveniente da produção de biodiesel pode ser efetivamente usada em dietas de frangos de corte em níveis de 2,5 ou $5,0 \%$. Também observaram que o uso da glicerina $10,0 \%$ resultou 
em redução do desempenho e pode ser relacionada com problemas com o fluxo de alimentação. A qualidade da glicerina também é uma preocupação, devido a que os níveis residuais de potássio podem ocasionar problemas como a retenção de líquidos ou desequilíbrios no balanço de eletrólitos na dieta. Finalmente, apontaram que devem ser tomados cuidados em relação à possível concentração residual de metanol. ${ }^{39}$

Em ruminantes, Schröder e Südekum utilizaram o glicerol como substância glicogênica em dieta para vacas com alta produção de leite. ${ }^{40}$ Observaram que o glicerol precursor da glicose é um componente alimentar excelente, pois melhorou o suprimento de energia e auxiliou na prevenção de problemas de cetose. O glicerol poderia servir como ingrediente tanto de concentrados peletizados como de dietas completas, mesmo quando incluído em forma impura como o proveniente da produção de biodiesel.

As transformações químicas possíveis para a glicerina são diversas, várias delas visam sua utilização como matéria-prima para a produção de insumos da cadeia petroquímica (plásticos) e produtos com aplicações no setor de combustíveis. Dentre as principais transformações químicas podem ser destacadas as dos acetais e cetais, que são substâncias obtidas da reação de alcoóis com aldeídos ou cetonas, respectivamente, sob ação de catalisadores ácidos. Os cetais e acetais derivados de glicerol têm aplicações diversas, dentre elas o uso como surfactantes, flavorizantes e solventes para uso em medicina, mas se destaca seu uso como aditivo para combustíveis. Os derivados produzidos nas reações com formaldeídos e acetona podem ser misturados à gasolina, melhorando as propriedades da queima. ${ }^{41}$ Outra importante transformação é a eterificação do glicerol, que produz compostos de menor polaridade e viscosidade e, por conseguinte, de maior volatilidade, fazendo com que os éteres de glicerol tenham inúmeras aplicações, sobretudo como aditivos para combustíveis e solventes. ${ }^{41}$

Uma das formas pelas quais pode acontecer a desidratação da glicerina é pela desidratação de sua hidroxila central que leva ao 3-hidroxi-propanal, o qual pode também sofrer desidratação para formar a acroleína. A acroleína é um importante intermediário para a produção de ácido acrílico que, por sua vez, é utilizado na produção de polímeros superabsorventes para uso em fraldas descartáveis, tintas, adesivos, objetos decorativos, entre outros. A acroleína também é usada na produção da metionina, aminoácido empregado na indústria alimentícia. ${ }^{41}$

Também não se pode deixar de mencionar a hidrogenólise do glicerol a 1,2 e 1,3 propanodiol (1,2 PD e 1,3 PD). O primeiro produto tem aplicação como agente anticoagulante e na produção de polímeros. Já o 1,3 PD é utilizado na produção de fibras sintéticas de poliésteres. Outra aplicação para a hidrogenólise da glicerina é numa rota para a produção de propeno, que é um importante insumo na produção de plásticos e consumido em larga escala no Brasil. ${ }^{41}$

Em muitas estações de tratamento de efluentes (ETEs) a quantidade de matéria orgânica degradável presente no efluente pode ser um fator limitante no processo de remoção de nitrogênio. Quando a taxa de DQO/N é menor a $3,4 \mathrm{~g}_{\mathrm{DQO}}$ por $\mathrm{g}_{\mathrm{N}}$, fontes de DQO extras devem ser adicionadas para remover o nitrato residual. A ausência da DQO para a desnitrificação pode ser compensada com a adição de efluentes concentrados, resíduos orgânicos ou compostos orgânicos. No entanto, o uso de algumas fontes externas de carbono pode derivar em um incremento nos custos operacionais.

O efluente de biodiesel ou a fração de glicerol é um substrato potencialmente adequado para o processo de desnitrificação de águas residuais. Este contém aproximadamente 56 a $60 \%$ de glicerol, 14 a $16 \%$ de bases em forma de sabões alcalinos e hidróxidos, 18 a $20 \%$ de metilato, 10 a $12 \%$ de metanol e 2 a $3 \%$ de água e outros compostos. ${ }^{42}$

Bodìk e colaboradores analisaram o efeito benéfico da adição de um efluente de biodiesel, como uma fonte de carvão externa, no tratamento biológico de águas residuais para complementar a remoção de nitrato no processo de desnitrificação destas águas. ${ }^{42} \mathrm{O}$ efluente de biodiesel empregado na pesquisa possuía concentrações de $\mathrm{DQO}=1,6 \times 10^{6} \mathrm{mg} \mathrm{L}^{-1}, \mathrm{~N}_{\text {Total }}=2 \mathrm{~g} \mathrm{~L}^{-1}, \mathrm{P}_{\text {Total }}=0,7 \mathrm{~g} \mathrm{~L}^{-1}, \mathrm{pH} 10,5$ e salinidade de $21 \mathrm{~g} \mathrm{~L}^{-1}$. Realizaram testes em escala de laboratório antes de aplicar o processo em uma ETE de Vrùtky, perto da cidade de Martin-Vrùtky, na República da Eslováquia. O reator operado no laboratório, de $2 \mathrm{~L}$ de capacidade, possuía misturador e foi alimentado em períodos alternados com o substrato $S_{1}$ (metanol, glicose, acetato de sódio e nutrientes) e com o substrato $\mathrm{S}_{2}$, que era uma mistura do $\mathrm{S}_{1}$ enriquecido com o efluente de biodiesel $(6,7 \mathrm{~mL}$ da solução do efluente de biodiesel com DQO $=1,5 \times 10^{4} \mathrm{mg} \mathrm{L}^{-1}$ em $500 \mathrm{~mL}$ de substrato $S_{1}$ ).

Durante o $1^{\circ}$ e $3^{\circ}$ períodos (sem adição do substrato $S_{2}$ ), a média dos valores da soma das concentrações de nitrito e nitrato $\left(\mathrm{NO}_{x}-\mathrm{N}\right)$ no afluente foi de 25,03 e $31,3 \mathrm{mg} \mathrm{L}^{-1}$, respectivamente. Durante o $2^{\circ}$ e $4^{\circ}$ períodos (com adição de substrato $S_{2}$ ), a média dos valores da soma das concentrações de $\mathrm{NO}_{\mathrm{x}}-\mathrm{N}$ foi de 9,5 e $10,9 \mathrm{mg} \mathrm{L}^{-1}$, respectivamente. Durante o $2^{\circ}$ e $4^{\circ}$ períodos o processo de desnitrificação mostrou uma eficiência de remoção de $\mathrm{NO}_{\mathrm{x}}-\mathrm{N}$ superior a $60 \% \mathrm{em}$ comparação com o $1^{\circ}$ e $3^{\circ}$ períodos, onde não foi empregado o substrato $\mathrm{S}_{2}$. Estes resultados sugerem que é necessária uma DQO de 5 a $10 \mathrm{mg}$ para a desnitrificação de $1,31 \times 10^{-5} \mathrm{~mol}$ de $\mathrm{NO}_{3}-\mathrm{N}$.

Os testes de adição do efluente de biodiesel realizados na ETE de Vrùtky foram feitos em duas fases. Na primeira, a dosagem do efluente de biodiesel foi de $200 \mathrm{~L}$ por dia na entrada do segundo tanque de desnitrificação, onde a concentração de $\mathrm{NO}_{3}-\mathrm{N}$ era em média de $1,80 \times 10^{-4} \mathrm{~mol} \mathrm{~L}^{-1}$. Após a dosagem do efluente de biodiesel foi detectado um decréscimo quase instantâneo; os valores médios registrados da concentração de $\mathrm{NO}_{3}-\mathrm{N}$ foram de $8,55 \times 10^{-5} \mathrm{~mol} \mathrm{~L}^{-1}$. As concentrações iniciais de $\mathrm{NO}_{3}-\mathrm{N}$ variaram na faixa de $7,89 \times 10^{-5}$ $1,31 \times 10^{-4} \mathrm{~mol} \mathrm{~L}^{-1}$ e a eficiência de desnitrificação nesta primeira fase aumentou em $6,58 \times 10^{-5} \mathrm{~mol}_{\mathrm{NO} 3-\mathrm{N}} \mathrm{L}^{-1}$ por $100 \mathrm{~L}$ de substrato adicionado. Na segunda fase a dosagem do efluente de biodiesel foi de $500 \mathrm{~L}$ por dia na entrada do primeiro tanque de desnitrificação. O volume deste tanque foi duas vezes maior do que o tanque onde foi realizada a primeira fase de dosagem. Após a adição do efluente de biodiesel, um decréscimo quase imediato foi detectado; os valores médios da concentração de $\mathrm{NO}_{3}-\mathrm{N}$ foram de $1,05 \times 10^{-4} \mathrm{~mol} \mathrm{~L}^{-1}$. Contudo, os autores obtiveram concentrações de $\mathrm{NO}_{3}-\mathrm{N}$ inferiores a $1,31 \times 10^{-4} \mathrm{~mol} \mathrm{~L}^{-1}$, mas a eficiência de desnitrificação nesta segunda fase $\left(2,63 \times 10^{-5} \mathrm{~mol}_{\mathrm{NO} 3-\mathrm{N}} \mathrm{L}^{-1}\right.$ por $100 \mathrm{~L}$ de substrato adicionado $)$ foi inferior à registrada na primeira fase.

Por outro lado, Álvarez e colaboradores estudaram a codigestão de uma mistura de resíduos da qual o efluente de biodiesel fazia parte e que serviu para melhorar a eficiência de um processo de digestão anaeróbica usado na produção de biogás (rico em metano).$^{43}$ Neste caso, a determinação da melhor proporção da mistura é de grande importância para poder maximizar a produção de metano, evitar processos de inibição e tornar rentáveis as plantas de biogás.

Os autores desenvolveram uma metodologia que determina as proporções mais adequadas dos cossubstratos para que forneçam um potencial de biodegradação otimizado. Assim, desenvolveram um método de otimização de programação linear baseado na determinação de restrições (valores máximos e mínimos) de várias características da mistura. Esta mistura foi composta por três substratos (esterco de suíno, resíduos de peixe e efluente de biodiesel) com características diferentes.

O método Solver do software Excel ${ }^{\mathrm{TM}}$ foi empregado para realizar a programação linear e consistia em maximizar uma função objetiva, tomando em conta várias restrições. Duas funções objetivas foram consideradas: o potencial total de biodegradação do substrato 
(considerando a eficiência de transformação do substrato) e o potencial biocinético (considerando a capacidade cinética do processo anaeróbio). Como resultado desta otimização que correspondia a uma série particular de restrições, o programa apresentou um conjunto de combinações com as frações que cada substrato deveria ter na mistura para se poder obter a máxima biodegradação e potencial biocinético.

Baseado nas características de cada substrato, o programa gerou seis diferentes proporções de misturas (A, B, C, D, E, F). Os experimentos com estas misturas foram realizados em frascos de $500 \mathrm{~mL}$ a temperatura controlada de $35^{\circ} \mathrm{C}$ e agitação de $120 \mathrm{rpm}$. Destas seis misturas, D e E apresentaram os melhores resultados. A mistura $\mathrm{E}$ (5\% resíduos de peixe, $11 \%$ efluente de biodiesel e $84 \%$ esterco de suíno) atingiu o maior potencial de biodegradação $\left(14,33 \mathrm{~mol} \mathrm{CH}_{4}\right.$ $\mathrm{kg}^{-1} \mathrm{DQO}$ ), enquanto que a mistura $\mathrm{D}$ (4\% resíduos de peixe, $8 \%$ efluente de biodiesel e $88 \%$ esterco de suíno) apresentou o maior potencial biocinético $\left(0,73 \mathrm{~mol} \mathrm{CH}_{4} \mathrm{~kg}^{-1}\right.$ DQO dia).

A escolha de uma destas misturas em uma planta hipotética de biogás dependerá do objetivo da planta. A mistura E proporcionará uma digestão mais estabilizada, enquanto que a mistura D levará a uma taxa de produção de metano mais elevada. ${ }^{43}$

Outro produto obtido a partir do efluente de biodiesel é o poli-hidroxibutirato (PHB). Dobroth e colaboradores empregaram combinações microbianas mistas enriquecidas para a produção deste produto. ${ }^{44} \mathrm{O} \mathrm{PHB}$, que exibe propriedades similares às do polipropileno, pertence à família dos poli-hidroxialcanoatos (PHA), os quais são termoplásticos biodegradáveis que podem ser sintetizados por micro-organismos como grânulos intracelulares. Estes PHAs são interessantes substitutos aos termoplásticos derivados do petróleo, cuja produção comercial requer grandes quantidades de combustíveis fósseis e emite mais gases com efeito de estufa. ${ }^{44}$

O inóculo empregado foi obtido de uma estação de tratamento de esgoto da cidade de Moscou nos Estados Unidos e o efluente de biodiesel (glicerol bruto) foi obtido de duas fontes: de uma planta piloto de produção de biodiesel da Universidade de Idaho (UI) e do Grupo de Energia GEN-X da cidade de Burbank, ambos nos Estados Unidos. O efluente de biodiesel da UI continha aproximadamente 3,85 mol L-1 de glicerol e 7,46 mol L-1 de metanol e o efluente do GEN-X continha uma concentração máxima de metanol de $6,90 \mathrm{~mol} \mathrm{~L}^{-1}$.

Diversos reatores foram operados para realizar a pesquisa e foram identificados com as iniciais BD (biodiesel) seguidas de um número. A matriz de operação dos reatores inclui três tempos de residência sólidos (10, 20, 30 dias), quatro tempos de residência hidráulicos (6, $8,20,30$ dias) e três ciclos $(4,5,10$ dias). Todos os reatores foram operados aerobiamente e em mistura contínua. Um substrato composto de $10 \%$ de glicerol e $90 \%$ de água de torneira (v/v) foi adicionado no início de cada ciclo. Foi adicionada uma solução de cloreto de amônio $\left(2,80 \mathrm{~mol} \mathrm{~L}^{-1}\right)$ como fonte de nitrogênio.

As investigações iniciais focaram a determinação das condições operacionais ótimas dos reatores para manter os micro-organismos estáveis e com capacidade de sintetizar PHA. Nesta primeira parte, a alimentação nos reatores BD1-BD3 $(0,5 \mathrm{~L})$ foi feita com o efluente procedente da UI. Os desempenhos mostrados por estes confirmaram o potencial para gerar biomassa com alto teor de PHB (BD1: 30-59\%, BD2: $45-62 \%$ e BD3: 42-61\%). Na segunda parte da pesquisa foi empregado o efluente do GEN-X para alimentar os reatores BD7, $\mathrm{BD} 10$ e $\mathrm{BD} 13$, de escala maior (4 L), que eram réplicas dos reatores BD1-BD3, obtendo-se teores de PHB inferiores (BD7: 8-24\%, BD10: $14-37 \%$ e BD13: 5-15\%). Ao ser removido o metanol do efluente do GEN-X (BD13) observou-se a diminuição da síntese do PHB; resultados parecidos (5-8\% de PHB) foram obtidos quando o reator BD12 foi alimentado com glicerol puro. Os autores afirmam que os PHAs podem ser sintetizados pelas combinações microbianas mistas a partir de glicerol e metanol, embora desde um ponto de vista bioenergético os micróbios consumam preferencialmente o metanol devido ao alto estado de oxidação. ${ }^{44}$

Vários ciclos operacionais foram realizados no reator BD4 durante 5 dias para observar como era empregado o substrato na síntese do PHB. Estes testes mostraram que as concentrações de glicerol permaneceram relativamente constantes $\left(0,54 \mathrm{~mol} \mathrm{~L}^{-1}\right)$, enquanto que as do metanol foram diminuídas significativamente, muito próximas do esgotamento.

Como descrito nesta revisão, existem diversos métodos destinados ao tratamento do efluente de lavagem do biodiesel; alguns deles visam o tratamento, outros a geração de energia ou produtos ou, também, o enriquecimento de um substrato; estes tipos de tratamento, assim como as eficiências de remoção, os tempos de duração e os produtos gerados em cada processo estão sumarizados na Tabela 3. Através da análise dos dados desta tabela observa-se que, embora a remoção de SS e TOG seja bastante satisfatória nos efluentes tratados por eletrocoagulação, ${ }^{4,24}$ a remoção total dos compostos orgânicos ainda é baixa. $\mathrm{O}$ uso de um processo de codigestão anaeróbia no efluente tratado por eletrocoagulação melhorou a eficiência do processo na remoção da DQO,${ }^{30}$ embora longos tempos de tratamento sejam necessários.

Destaca-se também a elevada eficiência na remoção de DBO (90\%), DQO e TOG (100\%) obtidas por oxidação eletroquímica ${ }^{27}$ mostrando a importância deste tipo de tratamento. Os tratamentos biológicos também mostraram eficiências consideráveis com uma elevada redução da matéria orgânica e do óleo contido nos efluentes. ${ }^{26,28}$

Um tratamento que também se destacou foi o físico-químico, ${ }^{29}$ no qual a remoção de cor, turbidez, hidrocarbonetos e TOG foi total, entretanto os valores da DQO ainda não foram reduzidos totalmente.

No que diz respeito ao reaproveitamento dos compostos presentes (ou alguns deles) nos efluentes da produção de biodiesel, fica claro através da análise dos dados da Tabela 3 que é possível produzir desde eletricidade até compostos que são fortes candidatos a combustíveis considerados como renováveis como o $\mathrm{H}_{2}$, o metano e o etanol. Estes estudos são de elevada importância na busca por fontes alternativas de combustíveis.

\section{PATENTES}

Balagopal e colaboradores requereram, nos Estados Unidos, a patente de um processo para a produção de biodiesel que dispensa a etapa de lavagem com água para a retirada das impurezas. ${ }^{45}$ Este invento consiste na síntese do biodiesel utilizando uma discreta adição de metóxido de sódio $\left(\mathrm{NaOCH}_{3}\right)$ em um processo eletroquímico sendo que, em um único passo, pode ser produzido biodiesel, metilato de sódio e outros alcoolatos e também prevê a separação da glicerina e do excesso de $\mathrm{NaOH}$.

Segundo os autores ${ }^{45}$ a célula eletroquímica empregada para a produção do biodiesel foi dividida em dois compartimentos por uma membrana condutiva feita de material cerâmico impermeável à água. Uma solução aquosa de hidróxido de sódio e metanol forma o metóxido de sódio; o ânodo é constituído por um eletrodo do tipo ânodo dimensionalmente estável (ADE) e como cátodo é possível utilizar níquel, platina e prata em uma liga metálica sobre aço inox ou grafite.

Após a ativação da célula com a adição do óleo vegetal escolhido, os ésteres estarão separados do lado catódico da célula e assim não será necessária a lavagem destes. A Figura 5 apresenta uma visão simplificada do fluxo dos produtos no método de produção proposto.

Em janeiro de 2010, Maliszewski e colaboradores registraram nos Estados Unidos uma patente que visa a produção de biodiesel reduzindo substancialmente as emissões de águas residuais. ${ }^{46} \mathrm{De}$ acordo com os processos da invenção, a água usada para a lavagem do biodiesel bruto para remover metanol e glicerina é concentrada através de separação por membranas e fracionamento por destilação, 
Tabela 3. Tipos de tratamento do efluente de biodiesel, porcentagens de remoção, tempo usado e produtos gerados

\begin{tabular}{|c|c|c|c|c|}
\hline Tipo de tratamento & \% Remoção & Tempo de duração & Produtos gerados & Ref. \\
\hline Eletrocoagulação & $\begin{array}{c}\text { DQO: } 55,7 \\
\text { Glicerina: } 3,5 \\
\text { Metanol: } 16,9 \\
\text { SS: } 100 \\
\text { TOG: } 100\end{array}$ & $25 \mathrm{~min}$ & Nenhum & 4 \\
\hline Eletrocoagulação & $\begin{array}{c}\text { DQO: } 55,01 \\
\text { SS: } 96,75 \\
\text { TOG: } 97,76\end{array}$ & $23 \mathrm{~min}$ & Nenhum & 24 \\
\hline Oxidação eletroquímica & $\begin{array}{l}\text { DBO: } 90 \\
\text { DQO: } 100 \\
\text { TOG: } 100\end{array}$ & $7 \mathrm{~h}$ & Nenhum & 27 \\
\hline Biológico (Rhodotorula mucilaginosa) & Óleo: 98 & $66 \mathrm{~h}$ & Nenhum & 26 \\
\hline Biológico (inóculo: UASB - abatedouro de aves) & $\begin{array}{c}\text { Matéria orgânica: } 85 \% \\
\text { DQO: } 66-93\end{array}$ & $8 \mathrm{~h}$ & Nenhum & 28 \\
\hline Físico-químico $\left(\mathrm{Al}_{2}\left(\mathrm{SO}_{4}\right)_{3}\right)$ & $\begin{array}{c}\text { DQO: } 69 \\
\text { Cor, turbidez, } \\
\text { hidrocarbonetos } \\
\text { e TOG: } 100\end{array}$ & N.I. & Nenhum & 29 \\
\hline Eletrocoagulação + codigestão anaeróbia & DQO: 81 & $18-45 \mathrm{~h}$ & Metano & 30 \\
\hline Biológico (inóculo: águas residuais domésticas) & DQO: 90 & $700 \mathrm{~h}$ & $\begin{array}{c}\text { Eletricidade: } \\
2110 \pm 68 \mathrm{~mW} \mathrm{~m}^{-2} \\
\text { de cátodo }\end{array}$ & 31 \\
\hline Biológico (Bacillus subtilis) & N.I. & $600 \mathrm{~h}$ & Eletricidade: $0,06 \mathrm{~mW} \mathrm{~cm}^{-2}$ & 32 \\
\hline Neutralização com ácidos & N.I. & $30 \mathrm{~min}$ & Glicerol & 33 \\
\hline Biológico (inóculo: efluente de cervejaria) & Efetividade: 93 & $50 \mathrm{~h}$ & Metano & 34 \\
\hline Biológico (inóculo Enterobacter aerogenes) & Glicerol: 100 & $24 \mathrm{~h}$ & $\begin{array}{c}\mathrm{H}_{2} \\
\text { Etanol }\end{array}$ & 35 \\
\hline Biológico (inóculo Thermotoga neapolitana) & Glicerol: 27,3 & $50 \mathrm{~h}$ & $\mathrm{H}_{2}$ & 36 \\
\hline
\end{tabular}

N.I.: não informado

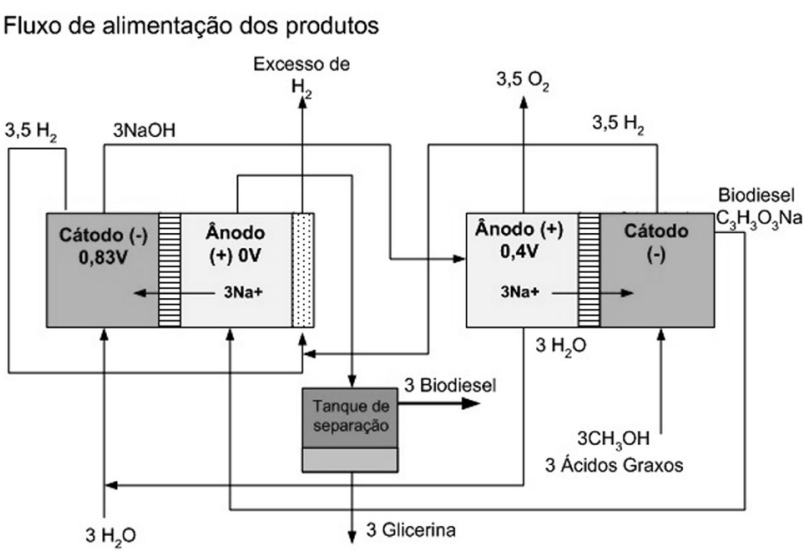

Figura 5. Visão simplificada do fluxo dos produtos na célula eletroquímica

proporcionando uma fração contendo pelo menos $30 \%$ em massa de glicerina, e outra fração aquosa com uma concentração reduzida de glicerina em comparação com a água de entrada. A fase aquosa com baixa concentração de glicerina pode ser descartada, ou, de preferência, reciclada como parte da água para lavar o biodiesel bruto.

O processo compreende:

a) o contato entre os triglicerídeos e o álcool na presença de um catalisador, sob condições de transesterificação (onde a taxa molar de álcool em relação aos triglicerídeos é de cerca de 3:1) proporciona como produto um biodiesel cru que contem ésteres alquílicos, glicerina e álcool. Os reagentes devem ficar em contato o tempo suficiente para poder converter aproximadamente $90 \%$ dos triglicerídeos em ésteres;

b) estes ésteres são separados da glicerina (por diferença de densidades) em um tanque de separação de fases;

c) o biodiesel bruto sofre fracionamento ao ser submetido a vapor de água, conseguindo retirar o álcool deste em baixa temperatura. Ao se aumentar a temperatura são retirados os triglicerídeos, a glicerina e os demais regentes;

d) o biodiesel é lavado (produzindo um biodiesel puro) e a água de lavagem submetida a diferentes condições de temperatura e pressão e separação por membrana, com o objetivo de concentrar os poluentes e recuperá-los para diferentes destinos. A água resultante deste último processo pode ser reutilizada no processo novamente.

Hwan e colaboradores registraram a patente de um método de tratamento da água residual do processo de lavagem do biodiesel através de filtragem por membranas; a técnica desenvolvida minimiza a obstrução da membrana, podendo tal membrana ser facilmente lavada. ${ }^{47} \mathrm{O}$ sistema pode ser mantido de maneira fácil e com reduzida mão de obra, reduzindo também a utilização de produtos químicos, como nitrogênio, fósforo e alcalinizantes. O método compreende três etapas: a) a água de lavagem é processada usando um reator biológico do tipo anaeróbio para a remoção dos nutrientes em duas fases: na primeira passa por um fermentador em meio ácido e na segunda, por um fermentador anaeróbio de metano. Ao final destas etapas se reduzem os compostos orgânicos da água de lavagem e se produz biogás;

b) trata-se a água que sai do processo anaeróbio passando-a através 
de um biorreator de membrana, o qual remove os componentes orgânicos que restaram da primeira etapa;

c) em uma terceira etapa de osmose reversa, o efluente é refinado efetuando a separação de álcalis, compostos nitrogenados, fósforo e vestígios de minerais, fazendo os mesmos voltarem ao reator biológico para realimentar o processo de digestão destes componentes.

Seiji e colaboradores registraram uma patente para tratar a matéria orgânica alcalina contida nas águas residuais da produção do biodiesel. ${ }^{48} \mathrm{O}$ método descrito compreende uma primeira etapa em que, em um tanque de mistura, um ácido é misturado ao efluente de biodiesel para ajustar o $\mathrm{pH}$ em 3. A segunda etapa é realizada em um tanque de separação e visa à remoção da fase oleosa que se encontra na superfície. Na terceira etapa o pH é ajustado entre 6 e 8 em um tanque com a adição de um sal alcalino no efluente livre do óleo. A quarta etapa tem como objetivo decompor a matéria orgânica em um tanque de tratamento biológico, no qual é injetado ar em seu interior. Na quinta e última etapa, a limpeza do efluente proveniente do processo anterior é feita em um tanque de sedimentação e separação, onde é removida toda matéria em suspensão.

Em 2011, Araujo e colaboradores registraram no Brasil a patente de um processo de produção de recobrimentos especiais a partir da glicerina, especialmente aquela proveniente da indústria de biodiesel. ${ }^{49}$ Esta glicerina permite o recobrimento de diferentes superfícies para a produção de camadas de carvão, em diferentes substratos, tais como vidros, metais ou até mesmo argilas como, por exemplo, montmorilonita e vermiculita.

O processo de preparação pode ser descrito como aquecimento controlado da mistura glicerina, catalisador e suporte, a temperaturas medianas que variam entre 150 e $420{ }^{\circ} \mathrm{C}$, para que ocorra a polimerização da glicerina e, aquecimento controlado, em atmosfera inerte, que pode atingir $900{ }^{\circ} \mathrm{C}$, para a formação de uma camada à base de carbono. Esse processo pode ocorrer tanto na superfície de um suporte, como isoladamente. Para aumentar a área superficial do material carbonáceo, utilizam-se métodos de ativação química e física, para atingir áreas superiores a $1600 \mathrm{~m}^{2} \mathrm{~g}^{-1} \mathrm{e}$ porosidade controlada (micro, meso ou macroporos).

Os autores apontam que no processo de obtenção dos materiais carbonáceos podem se utilizar catalisadores que favoreçam a polimerização e carbonização da glicerina, tais como, ácidos, bases, sais de metais de transição, óxidos metálicos, zeólitas e argilas. Para obter materiais com porosidade e área superficial controlada, utilizam-se métodos de ativação química - empregando $\mathrm{H}_{3} \mathrm{PO}_{4}, \mathrm{KOH}, \mathrm{ZnCl}_{2}$ e $\mathrm{H}_{2} \mathrm{SO}_{4}$, como agentes ativantes - e física - empregando $\mathrm{CO}_{2}$ e $\mathrm{H}_{2} \mathrm{O}$ como ativantes da superfície carbonácea.

Como discutido acima, as diversas patentes aqui apresentadas encaram o problema da geração da água de lavagem do biodiesel desde diversos ângulos; daí a sua importância, pois mostram a possibilidade de produção de biodiesel sem geração de efluentes líquidos. Assim também, mostram que se a tecnologia escolhida para a produção de biodiesel produz efluentes, é possível tratá-los por diversos métodos que podem agir de forma isolada ou pela combinação de processos e, inclusive, há a possibilidade do reaproveitamento destes para a geração de novos produtos.

\section{PERSPECTIVAS E CONSIDERAÇÕES FINAIS}

Como pôde ser visto, os estudos focados na degradação (remoção) dos poluentes contidos nos efluentes da produção de biodiesel são limitados (7 trabalhos) e recentes, com o primeiro artigo datado de 2005. Assim, fica evidente ser esta uma nova área de pesquisa que começa a ser desenvolvida.

Neste sentido, considerando a elevada eficiência obtida por oxidação eletroquímica realizada por aplicação de eletrodos de Ti/ $\mathrm{RuO}_{2}$ num reator em batelada com agitação magnética, novos estudos deverão ser realizados com o intuito de desenvolver e/ou utilizar novos materiais eletródicos, mais estáveis e eficientes, na oxidação de compostos orgânicos, como são os ADEs de diversas composições e os eletrodos de diamante dopado com boro. Novos desenhos e configurações de reatores, especialmente aqueles que trabalhem em fluxo contínuo, deverão ser desenvolvidos e testados com a finalidade de melhorar a transferência de massa dentro do reator e assegurar um maior contato entre o efluente e os eletrodos.

Por outro lado, os estudos baseados em tratamentos biológicos neste tipo de efluente poderão ser focados na diminuição dos fatores e/ou condições operacionais que inibem o crescimento microbiano, o que dificulta a degradação natural do efluente. Adicionalmente, é necessária a realização de estudos que visem reduzir o tempo dos processos biológicos, assim como também, minimizar a dependência da adição de fontes de nitrogênio ou aperfeiçoar as condições das culturas e criar novas espécies mutantes, seja por métodos de melhoramento convencional ou por engenharia genética, ${ }^{35}$ que possuam uma grande tolerância a altas concentrações de sais e glicerol.

Também foi visto que os tratamentos por eletrocoagulação conseguem remover significativamente sólidos suspensos e óleos e graxas do efluente, mas a remoção da DQO, metanol e glicerina nestes, é mais modesta. ${ }^{4,24,30}$ Portanto, este tratamento pode ser adotado como pré-tratamento do efluente de lavagem de biodiesel, mas ainda requer um tratamento secundário capaz de diminuir ainda mais as concentrações da DQO, metanol e glicerina. Desta forma, a combinação dos processos de eletrocoagulação e biológico ou eletrocoagulação e eletro-oxidação mostra-se interessante.

Por outro lado, pesquisas baseadas em métodos físico-químicos ou na combinação de dois ou mais processos para o tratamento deste efluente também foram ainda pouco exploradas, podendo ser o enfoque de estudos nos próximos anos.

Assim também, os estudos que mostram o uso dos poluentes gerados na produção de biodiesel (principalmente o glicerol) para a produção de hidrogênio ${ }^{35,36}$ e metano $^{34}$ são interessantes para aplicações futuras, desde que estes combustíveis sejam usados em sistemas não poluentes de produção de energia, estacionárias e não estacionárias, como são as células a combustíveis que funcionem diretamente oxidando hidrogênio no ânodo. ${ }^{50}$ Deve ser também considerado que o metano pode ser facilmente transformado em hidrogênio via reforma em fase vapor ou por decomposição catalítica ou térmica. ${ }^{51,52}$

Finalmente, do ponto de vista industrial, a viabilidade econômica de diversos tipos de tratamento deverá ser avaliada, visando, além de alcançar elevadas eficiências na remoção, recuperação ou reuso dos poluentes, conhecer os custos inerentes a cada processo para a obtenção de uma maior quantidade de informações dos processos.

\section{AGRADECIMENTOS}

Ao Conselho Nacional de Desenvolvimento Científico e Tecnológico - CNPq (Proc.: 304018/2009-0 e 310669/2010-3) pelas bolsas concedidas.

\section{REFERÊNCIAS}

1. Demirbas, A.; Biodiesel: a realistic fuel alternative for diesel engines, Springer-Verlag London Limited: Espanha, 2008; http://www. bioecon.com/bichem.html, acessada em Julho 2011; http://www. greencarcongress.com/2010/07/petrobras-partners-with-bioecon-onbichem-process-for-cellulosic-biofuels-and-chemicals.html, acessada em Julho 2011.

2. Reijnders, L.; Energ. Policy 2006, 34, 863. 
3. Puppan, D.; Per. Pol. Soc. Man. Sci. 2002, 10, 95.

4. Srirangsan, A.; Ongwandee, M.; Chavalparit, O.; Environ. Asia 2009, 2, 15.

5. Knothe, G.; van Gerpen, J.; Krahl, J.; The Biodiesel Handbook, AOCS Press: Champaing, 2005; Janaun, J.; Ellis, N.; Renew. Sust. Energ. Rev. 2010, 14, 1312.

6. Fukuda, H.; Kondo, A.; Noda, H.; J. Biosci. Bioeng. 2001, 92, 405; Leung, D. Y. C.; Wu, X.; Leung, M. K. H.; Appl Energ. 2010, 87, 1083; Avellaneda, F.; Salvadó, J.; Fuel Process Technol. 2011, 92, 83; Demirbas, A.; Energ. Convers. Manage. 2008, 49, 125; Miao, X.; Li, R.; Yao, H.; Energ. Convers. Manage. 2009, 50, 2680.

7. Vicente, G.; Martínez, M.; Aracil, J.; Bioresour. Technol. 2004, 92, 297; Guo, F.; Peng, Z.; Dai, J.; Xiu, Z.; Fuel Process Technol. 2010, 91, 322; Lukić, I.; Krstić, J.; Jovanović, D.; Skala, D.; Bioresour. Technol. 2009, 100, 4690; Kim, H.; Kang, B.; Kim, M.; Park, Y.; Kim, D.; Lee, J.; Lee, K.; Catal. Today 2004, 93-95, 315; Rashtizadeh, E.; Farzaneh, F.; Ghandi, M.; Fuel 2010, 89, 3393.

8. Demirbas, A.; Energ. Convers. Manage. 2007, 48, 937; Demirbas, A.; Biomass Bioenerg. 2009, 33, 113; Demirbas, A.; Prog. Energ. Combust. 2005, 31, 466.

9. Tomei, J.; Upham, P.; Energ. Policy 2009, 37, 3890; Alcantara, R.; Amores, J.; Canoira, L.; Fidalgo, E.; Franco, M. J.; Navarro, A.; Biomass. Bioenerg. 2000, 18, 515.

10. Royon, D.; Daz, M.; Ellenrieder, G; Locatelli, S.; Bioresour. Technol. 2007, 98, 648; Nabi, N. Md.; Rahman, M. Md.; Akhter, S. Md.; Appl. Thermal. Eng. 2009, 29, 2265; Keskin, A.; Altiparmak, M. G. D.; Aydin, K.; Renew. Energ. 2008, 33, 553.

11. Hameed, B. H.; Lai, L. F.; Chin, L. H.; Fuel Process Technol. 2009, 90, 606; Pleanjai, S.; Gheewala, S. H.; Appl. Energ. 2009, 86, S209.

12. Issariyakul, T.; Kulkarni, M. G.; Meher, L. C.; Dalai, A. K.; Bakhshi, N. N.; Chem. Eng. J. 2008, 140, 77.

13. Kaya, C.; Hamamci, C.; Baysal, A.; Akba, O.; Erdogan, S.; Saydut, A.; Renew Energ. 2009, 34, 1257; Nguyen, T.; Do, L.; Sabatini, D. A.; Fuel 2010, 89, 2285; Pérez, A.; Casas, A.; Fernández, C. M.; Ramos, M. J.; Rodríguez, L.; Bioresour. Technol. 2010, 101, 7375.

14. Marchetti, J. M.; Errazu, A. F.; Biomass. Bioenerg. 2008, 32, 892.

15. Nakpong, P.; Wootthikanokkhan, S.; Renew. Energ. 2010, 35, 1682; Oliveira, J. F. G.; Lucena, I. L.; Saboya, R. M. A.; Rodrigues, M. L.; Torres, A. E. B.; Fernandes, F. A. N.; Cavalcante Jr, C. L.; Parente Jr., E. J. S.; Renew. Energ. 2010, 35, 2581; Kumar, D.; Kumar, G.; Poonam; Singh, C. P.; Ultrason. Sonochem. 2010, 17, 555.

16. Andersen, O.; Weinbach, J-E.; Biomass. Bioenerg. 2010, 34, 1183; Tashtoush, G. M.; Al-Widyan, M. I.; Al-Jarrah, M. M.; Energ. Convers. Manage. 2004, 45, 2697; da Cunha, M. E.; Krause, L. C.; Moraes, M. S. A.; Faccini, C. S.; Jacques, R. A.; Almeida, S. R.; Rodrigues, M. R. A.; Caramão, E. B.; Fuel Process Technol. 2009, 90, 570.

17. Enweremadu, C. C.; Mbarawa, M. M.; Renew. Sus. Energ. Rev. 2009, 13, 2205 .

18. Mata, T. M.; Martins, A. A.; Caetano, N. S.; Renew. Sus. Energ. Rev. 2010, 14, 217; Ahmad, A. L.; Mat Yasin, N. H.; Derek, C. J. C.; Lim, J. K.; Renew. Sus. Energ. Rev. 2011, 15, 584; Brennan, L.; Owende, P.; Renew. Sus. Energ. Rev. 2010, 14, 557; Huang, G. H.; Chen, F.; Wei, D.; Zhang, X. W.; Chen, G.; Appl. Energ. 2010, 87, 38; Singh, J.; Gu, S.; Renew. Sus. Energ. Rev. 2010, 14, 2596; Morowvat, M. H.; RasoulAmini, S.; Ghasemi, Y.; Bioresour. Technol. 2010, 101, 2059.

19. Demirbas, A.; Energ. Convers. Manage. 2009, 50, 923.

20. Lam, M. K.; Lee, K. T.; Mohamed, A. R.; Biotechnology Advances 2010, 28,500 .

21. Quesada-Medina, J.; Olivares-Carrillo, P.; J. Supercrit. Fluids 2011, 56, 56.
22. Ma, F.; Hanna, M. A.; Bioresour. Technol. 1999, 70, 1.

23. Stidham, W. D.; Seaman, D. W.; Danzer, M. F.; US pat. 6,127,560 2000; Wimmer, T.; US pat. 5,399,731 1995.

24. Chavalparit, O.; Ongwandee, M.; J. Environ. Sci. 2009, 21, 1491.

25. De Boni, L. A. B.; Goldani, E.; Milcharek, C. D.; Santos, F. A. Dos; Periódico Tchê Química 2007, 4, 41.

26. Suehara, K.; Kawamoto, Y.; Fujii, E.; Khoda, J.; Nakano, Y.; Yano, T.; J. Biosci. Bioeng. 2005, 100, 437.

27. Pattaraluk, J.; Sangkorn, K.; Mali, H.; Energ. Convers. Manag. 2010, $51,531$.

28. Selma, V. C.; Cotrim, L. H. B.; Rodrigues, J. A. D.; Ratusznei, S. M.; Zaiat, M.; Foresti, E.; Appl. Biochem. Biotechnol. 2010, 162, 2365.

29. Goldani, E.; De Boni, L. A. B.; Frankenberg, C. L. C.; Cantelli, M.; Anais do II Simpósio Estadual de Agroenergia - II Reunião Técnica Anual de Agroenergia, Porto Alegre, Brasil, 2008.

30. Siles, J. A.; Martín, M. A.; Chica, A. F.; Martín, A.; Bioresour. Technol. 2010, 101, 6315.

31. Feng, Y.; Yang, Q.; Wang, X.; Liu, Y.; Lee, H.; Ren, N.; Bioresour. Technol. 2011, 102, 411.

32. Nimje, V. R.; Chen, Ch.-Y.; Chen, Ch.-Ch.; Chen, H.-R.; Tseng, M.-J.; Jean, J.-S.; Chang, Y.-F.; Bioresour. Technol. 2011, 102, 2629.

33. Hájek, M.; Skopal, F.; Bioresour. Technol. 2010, 101, 3242.

34. Siles, J. A. L.; Martín, M. A. S.; Chica, A. F. P.; Martín, A. M.; Bioresour. Technol. 2009, 100, 5609 .

35. Ito, T.; Nakashimada, Y.; Senba, K.; Matsui, T.; Nishio, N.; J. Biosci. Bioeng. 2005, 100, 260.

36. Ngo, T. A.; Kim, M-S.; Sim, S. J.; Int. J. Hydrogen Energy 2010, 36, 5836.

37. Freitas, L.; Santos, J. C.; Barcza, M. V.; de Castro, H. F.; Quim. Nova 2009, 32, 2277.

38. Abdalla, A. L.; da Silva, F. J. C.; de Godoi, A. R.; de Almeida, C. C.; de Paula, J. L. E.; R. Bras. Zootec. 2008, 37, 260.

39. Cerrate, S.; Yan, F.; Wang, Z.; Coto, C.; Sacakli, P.; Waldroup, P. W.; Int. J. Polut. Sci. 2006, 5, 1001.

40. Schröder, A.; Südekum, K. H.; Papers, $10^{\text {th }}$ International Rapeseed Congress, Canberra, Australia, 1999.

41. Mota, C. J. A.; da Silva, C. X. A.; Gonçalves, V. L. C.; Quim. Nova 2009, 32, 639.

42. Bodík, I.; BlšŤ́áková, A.; Sedláček, S.; Hutňan, M.; Bioresour. Technol. 2009, 100, 2452.

43. Álvarez, J. A.; Otero, L.; Lema, J. M.; Bioresour. Technol. 2010, 101, 1153.

44. Dobroth, Z. T.; Hu, S.; Coats, E. R.; McDonald, A. G.; Bioresour. Technol. 2011, 102, 3352.

45. Balagopal, S. H.; Pendleton, J. K.; Joshi, A. V.; US pat. 46,784 2007.

46. Maliszewski, T. A.; Bunning, D. L.; Schreck, D. J.; Kapicak, L. A.; Balmer, N. L.; US pat. 0126060A1 2010.

47. Hwan, R. D.; Jin, E. Y.; Eun, L. Y.; Jpn. JP2008023411 (A) 2009

48. Seiji, Y.; Masashiro, H.; Naohiko, U.; Kiyoshi, S.; Jpn. JP2008023411 (A) 2008.

49. Araujo, M. H.; Medeiros, M. A.; Lago, R. M.; Br PI 0902240-6, 2011.

50. Peighambardoust, S. J.; Rowshanzamir, S.; Amjadi, M.; Int. J. Hydrogen Energy 2010, 35, 9349.

51. Abbas, H. F.; Wan Daud, W. M. A.; Int. J. Hydrogen Energy 2010, 35, 1160 .

52. Oliveira, E. L. G.; Grande, C. A.; Rodrigues, A. E.; Chem. Eng. Sci. 2010, 65, 1539 . 